University of Wollongong

Research Online

Faculty of Business - Papers (Archive)

Faculty of Business and Law

2013

Development and validation of an instrument to measure user perceived service quality of mHealth

Shahriar Akter

University of Wollongong, sakter@uow.edu.au

John D'Ambra

University of New South Wales

Pradeep Ray

University Of New South Wales, p.ray@unsw.edu.au

Follow this and additional works at: https://ro.uow.edu.au/buspapers

Part of the Business Commons

Research Online is the open access institutional repository for the University of Wollongong. For further information contact the UOW Library: research-pubs@uow.edu.au 


\title{
Development and validation of an instrument to measure user perceived service quality of mHealth
}

\author{
Abstract \\ The role of service quality in fostering the growth of mHealth services has gained much attention in the \\ academic and practitioner communities. However, empirical research in this area has been beset by \\ inadequate conceptualization and the lack of a validated scale. This study addresses these limitations by \\ theoretically conceptualizing and empirically validating a multidimensional service quality scale in the \\ mHealth context. The findings show that mHealth service quality is a hierarchical, multidimensional, and \\ reflective construct, which consists of three primary dimensions and eight subdimensions. The results \\ also confirm that the mHealth service quality scale is more effective at predicting satisfaction and \\ continuance in a nomological network. \\ Keywords \\ era2015 \\ Disciplines \\ Business

\section{Publication Details} \\ Akter, S., D'Ambra, J. \& Ray, P. (2013). Development and validation of an instrument to measure user \\ perceived service quality of mHealth. Information and Management, 50 (4), 181-195.
}




\title{
Development and Validation of an Instrument to Measure User Perceived Service Quality of mHealth
}

\begin{abstract}
The role of service quality in fostering the growth of mHealth services has gained much attention in academic and practitioner communities. However, empirical research in this area has been beset by inadequate conceptualization and the lack of a validated scale. This study addresses these limitations by theoretically conceptualizing and empirically validating a multidimensional service quality scale in the mHealth context. The findings show that the mHealth service quality is a hierarchical, multidimensional, and reflective scale, which consists of three primary dimensions and eight subdimensions. The results also confirm that the mHealth service quality scale can better predict satisfaction and continuance in a nomological network.
\end{abstract}

Keywords: service quality, scale development, mobile health, satisfaction, continuance intentions, PLS path modeling. 


\section{Introduction}

mHealth, a new paradigm of an emerging information technology (IT) artifact, transforms healthcare delivery around the world by making it more accessible, affordable and available. Mounting interests in the field can be traced to the explosive growth of mobile communications over the past decade, which offer the promise of the promotion of health care in resource-poor settings $[1,2]$. The term 'mHealth' implies the use of mobile communications—such as personal digital assistants (PDAs) and mobile phones_for health information services [2]. mHealth has inherently provided greater flexibility and mobility by ensuring right-time information services to the right person at the right place [3-7]. It is seen as an enabler of change in the healthcare sector shifting the care paradigm from crisis intervention to promoting wellness, prevention, and self-management $[1,2]$. Although mHealth transforms healthcare delivery around the world, there are growing concerns, however, about the perceived quality of such services due to the lack of reliability of the system, the lack of knowledge and competence of the provider, and the lack of privacy and security of information services. Perceived quality is defined as the users' (or patients') judgment of, or impression about, the overall excellence or superiority of an mHealth service [8]. This quality perception is currently at the forefront of all attention because it is being seen as a means through which to increase its adoption and continuance and, ultimately, an approach through which to achieve better health outcomes for patients $[1,8]$. Undoubtedly, quality perceptions have a strong influence on one's inclination to avail health services because health concerns are among the most salient of all human concerns [9]. If the system cannot be trusted to guarantee a threshold level of quality, this will have a negative impact on satisfaction and continuance intentions. As a result, mHealth service providers are struggling to develop 
meaningful patient-oriented quality assessment measures and their impact on outcome constructs [1].

Although there are several service quality scales in the e-services domain $[37,61]$, much of this research has focused on the development of generic service quality models. Despite frequent indications that service quality needs to be context dependent, relatively few studies have undertaken the development of such context-specific measures [12-14]. As such, there is evidence of many failed attempts to measure service quality by applying generic service quality scales in new contexts [8]. It is worth noting that previous service quality scales were not specifically designed for use in the mHealth setting: these may not be entirely appropriate as service quality is a dynamic, multidimensional concept $[10,11]$ and the evaluation of these scales should be context dependent [8, 12-14]. Furthermore, given the innovative nature of mHealth services and the infancy of mHealth implementation, there is a paucity of reliable and valid instruments which adequately capture the dimensions of this ubiquitous healthcare paradigm. Overall, poor theoretical development, inadequate conceptualization of constructs and a lack of valid operationalization of measures have aggravated the pursuit of the scale development process in this context.

The main purpose of this study is to develop and validate a multidimensional, hierarchical service quality scale for measuring mHealth service quality in our research context and to investigate its ability to predict critical service outcomes in a nomological network. Accordingly, our specific objectives are, firstly, to conceptualize the nature and dimensions of the service quality construct. Secondly, we aim to systematically develop a scale to measure service quality from the patients' perspective in the mHealth domain. Our third objective is to assess the 
psychometric properties of the mHealth service quality scale. Fourthly, we aim to examine the nomological validity of the scale by assessing its association with satisfaction and continuance intentions. Overall, the study concludes by discussing the research implications, limitations and future research directions of service quality modeling in the mHealth context.

\section{Background}

\section{1. mHealth Service}

mHealth is generally defined as the use of portable devices with the capability of creating, storing, retrieving, and transmitting data in real time between end-users for the purpose of improving patient safety and quality of care [2]. Whereas eHealth is defined as the embryonic convergence of wide-reaching technologies such as the Internet, computer telephony/interactive voice response, wireless communications, direct access to healthcare providers, care management, education and wellness (DeLuca \& Enmark 2000), mHealth is defined as using mobile communications - such as PDAs and mobile phones-for health services and information. Recently, researchers have extended the definition of mHealth by focusing on any wireless technologies (e.g., Bluetooth, GSM, GPRS/3G, wiFi, WiMAX) to transmit various health-related data content and services through mobile devices such as mobile phones, smartphones, PDAs, laptops and Tablet PCs [15]. Table 1 synthesizes the unique attributes of mHealth that make it distinctive from other healthcare paradigms. In addition, this platform is relatively inexpensive, faster and simpler than other platforms to set up in any environment. At the moment, with massive penetration of mobile phone networks globally and the availability of low-cost smartphones, the majority of the global population (more than 5.5 billion people) have access to right-time communication and information services [15]. This ubiquity is a central element in the promise of the mobile platform for health care. 
Table 1: Unique attributes of mHealth

\begin{tabular}{|c|c|c|}
\hline Attributes & Implications & Study \\
\hline Accessibility & $\begin{array}{l}\text { mHealth provides ubiquitous, universal and } \\
\text { unison accessibility for any-time anywhere } \\
\text { solutions. }\end{array}$ & $\begin{array}{l}\text { Bauer et al. [95], Varshney [7], Kahn } \\
\text { [101] }\end{array}$ \\
\hline $\begin{array}{l}\text { Personalized } \\
\text { solutions }\end{array}$ & $\begin{array}{l}\text { mHealth provides individualized solutions } \\
\text { to address the specific needs of a specific } \\
\text { person based on their profile. }\end{array}$ & $\begin{array}{l}\text { Barnes [96], Barnes \& Scornavacca } \\
\text { [97] }\end{array}$ \\
\hline Immediacy & $\begin{array}{l}\text { mHealth provides right-time services } \\
\text { focusing on relevant, targeted and timely } \\
\text { information. }\end{array}$ & $\begin{array}{l}\text { Barnes \& Scornavacca [97], Barwise } \\
\text { \& Strong [98],Pousttchi \& Widemann } \\
\text { [99] }\end{array}$ \\
\hline $\begin{array}{l}\text { Location-based } \\
\text { information }\end{array}$ & 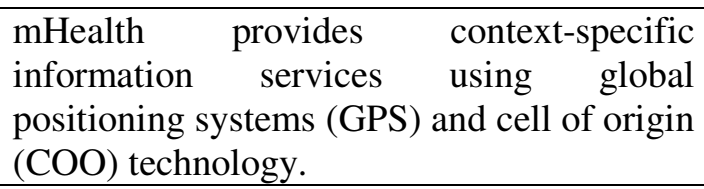 & $\begin{array}{l}\text { Barnes [96], Varshney [7], Kahn } \\
\text { [101] }\end{array}$ \\
\hline Interactivity & $\begin{array}{l}\text { mHealth creates value co-creation through } \\
\text { long-term and more intense two-way } \\
\text { interaction. }\end{array}$ & Akter [1], Barnes [96], Kahn [101] \\
\hline Mobility & $\begin{array}{l}\text { mHealth serves the needs for temporal, } \\
\text { spatial and contextual mobility. }\end{array}$ & $\begin{array}{l}\text { Kakihara \& Sorensen } \quad[100], \\
\text { Chatterjee et al. [4] }\end{array}$ \\
\hline
\end{tabular}

There is widespread evidence that mHealth can scale well to combat the evolving healthcare challenges by ensuring lower cost, wider access and better solutions [16]. It is expected that mHealth will soon transform the face and context of healthcare delivery around the world by improving overall patient care and the provision of personalized health services [17]. As a result, a growing number of countries worldwide are using mobile communications to address various healthcare needs, such as, education and awareness, remote data collection, remote monitoring, communication and training, disease and outbreak tracking, and diagnostic and treatment support. A recent study shows that at present there are 51 large-scale mHealth programs being operated in 26 developing countries around the world [2]. Although these programs are experiencing higher adoption because of their widespread access and cost-effective solutions, 
they require immediate assessment to measure the service quality and its effect on service outcomes $[1,2,15,18-22]$. Despite the profound importance of service quality, there is a paucity of research which has developed and applied metrics to analyze this relationship [1]. A review of the literature (see Table 2) reveals that this area has been under-researched and most of the literature remains largely fragmented and anecdotal $[1,4,15]$. Therefore, it is necessary to explore 'service quality in mHealth' in order to develop a comprehensive and parsimonious scale for such ubiquitous health services.

Table 2: Literature related to mHealth

\begin{tabular}{|l|l|l|}
\hline Study & Year & Subject area \\
\hline Ammenworth et al. [23] & 2000 & Application of mobile work in health care \\
\hline Maglaveras et al. [24] & 2002 & Mobile telemedicine for home care \\
\hline Hameed [25] & 2002 & General application of mobile computing health care \\
\hline Varshney [7] & 2005 & Pervasive health care \\
\hline Varshney [26] & 2006 & General application of wireless technology in health care \\
\hline Jen et al. [27] & 2007 & $\begin{array}{l}\text { Mobile (information and communications technology) ICT for } \\
\text { a hospital outpatient service }\end{array}$ \\
\hline Varshney [28] & 2008 & Wireless patient monitoring with emergency messages \\
\hline Patrick et al. [29] & 2008 & Challenges of using mobile phone for health \\
\hline Junglas et al. [5] & 2009 & Mobile ICT for frontline health employees \\
\hline Lorenz \& Oppermann [30] & 2009 & Mobile phone-based healthcare monitoring for the elderly \\
\hline Chatterjee et al. [4] & 2009 & Success factors for mobile work in health care \\
\hline Ahluwalia \& Varshney [3] & 2009 & Composite service quality in pervasive health care \\
\hline Sneha \& Varshney [6] & 2009 & Ubiquitous patient monitoring \\
\hline Ivatury et al. [111] & 2009 & Mobile telemedicine in developing countries \\
\hline Han et al. [31] & 2010 & Mobile ubiquitous health service scenario design \\
\hline Akter et al. [1] & 2010 & Service quality of mHealth \\
\hline Kahn et al. [101] & 2010 & Applications, opportunities and challenges \\
\hline Curioso \& Mechael [112] & 2010 & Collaboration between health care and IT \\
\hline Feder [113] & 2010 & mHealth solutions in developing countries \\
\hline Akter \& Ray [15] & 2010 & Applications and challenges of mHealth \\
\hline WHO [114] & 2011 & mHealth: challenges, opportunities and applications \\
\hline
\end{tabular}

\subsection{An Overview of Service Quality}


This section argues that the service quality of mHealth is an interdisciplinary domain which needs to be explored through generic theories from marketing, information systems (IS) and healthcare literature [1]. In this section, this study discusses the definitions and the nature of service quality, service quality theories in the healthcare domain, and the effects of service quality respectively.

\subsubsection{Defining service quality}

This study focuses on the perceived service quality of mHealth services, which is defined as consumers' (or patients') judgment about the overall excellence or superiority of a mobile health service [32]. Service quality has also been defined as measuring performance against expectations [33] or the gap between expected and perceived service [34] or performance only measures [11, 12, 14, 35]. The European Union's Research \& Development in Advanced Communications technologies in Europe (RACE) program [36] defines service quality as "a set of user perceivable attributes of that which makes a service what it is. It is expressed in userunderstandable language and manifests itself as a number of parameters, all of which have either subjective or objective values". In fact, all of these notions of service quality are interrelated and based on the consumer's perceptions [21]. Thus, we define service quality in this study as a consumer's judgment of, or impression about, an mHealth platform's overall excellence or superiority [8]. It is generally specified as a multidimensional [11, 14] and hierarchical concept $[8,37]$ whose evaluations are likely to be context dependent $[12,13,38]$. The hierarchal structure suggests that service quality comprises several primary dimensions, which reflects a common theme represented by the higher-order globally perceived service quality construct. Early researchers conceptualized service quality as a second-order model [10, $34,39]$ while recent studies have modeled it as a third-order factor $[8,11,38]$ to capture multiple 
dimensions in a meaningful manner. Although the extant research has developed service quality as a generic model to be generalized over all settings, this has resulted in many failed attempts to replicate the existing theories in new settings $[11,34]$. Despite clear indications that service quality evaluations need to be context dependent $[12,13,38]$, there is a paucity of contextspecific service quality models.

\subsubsection{Service quality in health care}

In health care, most of the service quality research has focused on either Gronross's [39] twodimensional model (i.e., functional quality and technical quality) or on Parasuraman et al.'s [34] five-dimensional SERVQUAL model (i.e., reliability, cooperation, confidence, care and tangibles). In addition, a good number of studies have followed Donabedian's [40, 41, 42] model which measured service quality under two dimensions, that is, technical and interpersonal quality. According to this framework, technical quality refers to the application of medical science and technology to health care, while interpersonal quality refers to the interaction that occurs between the service provider and consumer. Aligned with these findings, Brook and Williams [43] put forward a conceptualization in which technical care reflects how well diagnostic and therapeutic processes are applied and interactive care is concerned with the interactive behavior between the service provider and user. In a similar vein, other researchers introduced service quality models in health care which embraced Donabedian's findings [43, 44, 45, 46]. In a recent study, Zineldin [47] expanded these conceptualizations and found support for five quality dimensions: technical quality, functional quality, quality infrastructure, quality interaction, and quality atmosphere. More recently, Dagger et al. [8] came up with a contextspecific, multidimensional and hierarchical model for measuring health service quality in general healthcare settings. They identified four primary dimensions (interpersonal, technical, 
environment, and administrative) and nine subdimensions (interaction, relationship, information, expertise, atmosphere, tangibles, timeliness, operation, and support) for measuring service quality in a hierarchical manner.

Table 3: Service quality dimensions in health care

\begin{tabular}{|c|c|c|c|}
\hline Area & Study & Year & Service quality dimensions in health care \\
\hline $\begin{array}{l}\text { General } \\
\text { health care }\end{array}$ & $\begin{array}{l}\text { Donabedian [40] } \\
\text { Andaleeb [9] } \\
\text { Zineldin [47] } \\
\text { Dagger et al. [8] }\end{array}$ & $\begin{array}{l}1992 \\
2001 \\
2006\end{array}$ & $\begin{array}{l}\text { Technical and interpersonal qualities. } \\
\text { Reliability, cooperation, confidence, care, tangibles. } \\
\text { Technical quality, functional quality, quality } \\
\text { infrastructure, quality interaction, and quality } \\
\text { atmosphere. } \\
\text { Interpersonal, technical, environmental, and } \\
\text { information quality. }\end{array}$ \\
\hline $\begin{array}{l}\text { Mobile } \\
\text { health care }\end{array}$ & $\begin{array}{l}\text { Varshney [7] } \\
\text { Chatterjee et al. [4] } \\
\text { Akter et al. [1] }\end{array}$ & $\begin{array}{l}2005 \\
2009 \\
2010\end{array}$ & $\begin{array}{l}\text { Information systems (IS), technological, managerial, } \\
\text { and medical perspectives. } \\
\text { System quality, content quality, and information } \\
\text { quality } \\
\text { Platform quality, interaction quality, and outcome } \\
\text { quality }\end{array}$ \\
\hline
\end{tabular}

Given that mHealth implementation is in its infancy, a review of the literature revealed that there were few studies which directly explored service quality in this domain. However, some researchers examined the predominant factors that influence quality perception in mobile health care (see Table 3). For example, Varshney [26] investigated the impact of the information systems (IS), technological, managerial and medical perspectives of wireless health care. Chatterjee et al. [4] studied mobile work in health care and identified some interesting quality dimensions under an IS success framework. In a recent study, Akter et al. [1] proposed a 
conceptual model of service quality in mHealth based on platform quality, interaction quality, and outcome quality.

\subsubsection{Effects of service quality on service outcomes}

Studies have found both a direct relationship between service quality and satisfaction and an indirect relationship between service quality and intention to use through satisfaction $[14,35,48$, 49, 50]. DeLone \& McLean [51] confirmed that service quality leads to satisfaction and increased satisfaction leads to future intentions to use. Rai et al. [52] in their study to assess the validity of DeLone and McLean's [51] and Seddon's [53] IS success models, found that satisfaction impacts IS use and a higher level of satisfaction creates greater user dependence on the system. In healthcare, satisfaction is viewed as more closely aligned with behavioral intentions. Satisfaction is typically modeled as mediating the relationship between service quality and intentions to use $[11,14,35,50]$. However, in this study, we focus on 'continuance intentions' instead of 'intentions to use', which is defined as the extent to which a service system is used on a continued basis [54, 55, 56 ]. Bhattacherjee [56] confirmed the significance of continuance intentions by citing that "long-term viability of an IS and its eventual success depend on its continued use rather than [its] first-time use”. In the similar spirit, Limayem et al. [56] and few other researchers $[57,58]$ identified intentions to continue using as a critical success parameter for service systems implementation. Therefore, this study intends to examine the effects of service quality on satisfaction and continuance intentions in order to assess the nomological validity of service quality scale in mHealth settings. 


\section{Instrument Development Process}

To develop an instrument to measure mHealth service quality, this study began by investigating commonly cited factors that influence service quality in mobile health care, as outlined in the previous section. Through this process, three primary dimensions were identified that reflect customers' (or patients') service quality perceptions, that is, system quality, interaction quality, and information quality. Firstly, system quality reflects the quality of the technical level of communication $[1,51,59,60]$. It also refers to the performance of any electronic platform in terms of its system efficiency, system reliability, and system privacy $[1,61]$. Secondly, interaction quality indicates the quality of interpersonal communication between patients and providers over a mobile platform which reflects the expertise, professionalism, and competency of a service provider in delivering a service [34]. The final primary dimension we identified is information quality which represents the utilitarian and hedonic benefits of information services [37]. Throughout our conceptual exploration, service quality was frequently cited as a multidimensional, hierarchical and context-specific construct; thus, we believed that several specific subdimensions would determine the initially identified primary dimensions. As a result, we conducted an exploratory qualitative study to explore the subdimensions and to confirm the contextual appropriateness of the primary dimensions identified in the literature.

\subsection{Qualitative study}

This study has focused on mobile telemedicine services in Bangladesh, which is one of the leading developing countries in the implementation of mHealth services. This study defines a mobile telemedicine service as a personalized and interactive health service over mobile phone, the main goal of which is to provide ubiquitous and universal access to medical advice and 
information to any patient $[1,15]$. In recent years, this particular business-to-consumer $(\mathrm{B} 2 \mathrm{C})$ mHealth platform has become very popular in the developing world (e.g., India, Bangladesh, Pakistan, Mexico, South Africa, Peru, etc.) and is serving millions by delivering right-time medical information services $[1,15,20]$. Currently, more than 44 million people in Bangladesh have access to such mHealth services provided by the two major mobile operators (i.e., Grameen Phone's Healthline service and Banglalink's Healthlink service) $[1,15,20]$. Under this platform, a patient can access this service at any time by dialing some unique digits (e.g., '789' in Bangladesh) from his/her mobile phone and receive health services in the form of medical information, consultation, treatment, diagnosis, referral, and counseling from registered physicians.

In our study, we obtained qualitative data from three focus group discussions (FGD) and 10 indepth interviews (DI) conducted with mHealth (hotline) consumers in Bangladesh. A total of 24 participants, eight per focus group, were involved in the focus group sessions. Participants ranged in age from 18 to 62 years and both genders had equal participation. Each FGD session was conducted by two moderators and lasted about 90 minutes. In addition, the 10 DIs were conducted to explore users' insights on our research agenda. In both cases, participants were recruited using convenient sampling in order to ensure productive findings and the richest data for scale development [8]. In each case, respondents were asked various questions to evaluate their service quality experiences. The answers were recorded, synthesized and categorized to identify the core dimensions and their association with satisfaction and continuance intentions. In our qualitative study, service quality was frequently identified as a multidimensional and hierarchical concept. Users expressed their opinion on different service-level attributes (e.g., "I 
can access mHealth platform whenever I want" or "The physician shows sincere interest to solve my problems," or "It is worthwhile having information services from this platform") under multiple dimensions. Throughout this process, we found support for three primary dimensions (i.e., system quality, interaction quality, and information quality) and eight subdimensions (system reliability, system efficiency, system privacy, confidence, cooperation, care, and utilitarian and hedonic benefits of information services). Although we developed the subdimensions under each primary dimension based on the themes identified in the qualitative study, consultation with the literature described in the next section was used to support our findings.

\subsubsection{System quality}

System quality refers to the user's perceptions regarding the technical level of communication $[51,59,60]$. Three core themes were found to constitute customers' perceptions of system quality in mHealth: these were termed as system reliability, system efficiency, and system privacy. The first theme, system reliability, defines the degree to which the mHealth platform is available on an 'any-time' and 'anywhere' basis [1, 62]. This was frequently referred to as a unique and crucial indicator of system quality in mHealth as suggested by the following comments; "I can access the mHealth platform whenever I want" and "I can receive health services right away." The second theme, system efficiency, describes the degree to which an mHealth platform is easy to use and able to meet the variety of needs $[61,63]$. This was a common point of discussion in the qualitative interviews as reflected by the following comments; "It is easy to use" and "It is able to meet my variety of needs." The final theme, system privacy, refers to the degree to which the mHealth platform provides security in 
protecting the health information provided to patients [7, 61]. In electronic health care, 'privacy' has always been cited as an important parameter for gaining reliance on the service platform [61]. Comments such as "It protects my personal information" and "It does not share information with others" highlight the importance of privacy in mobile health care.

\subsubsection{Interaction quality}

Interaction quality indicates the quality of the interaction and dyadic interplay between a service provider and a user $[8,11,39]$. This study proposes the interaction quality as it clearly indicates the mHealth service provider's ability to recognize and respond to the patient's stated or unstated needs, interests, and concerns which is an important aspect of service quality and an important part of the overall service experience [103]. According to Dagger et al. [8, p. 126], "[a]s services are produced, distributed, and consumed in the interaction between a service provider and a customer, the interpersonal process is crucial to the customer's ultimate perception of the service provider's performance". The interpersonal interaction that takes place during service consumption influences service quality perception to a large extent $[8,64,38]$. This study observed that when a user interacts with a physician under a mobile telemedicine platform, he or she perceives quality in terms of the knowledge and competence of the provider, promptness in providing solutions and the individual attention to his/her needs. This is defined as "a period of time during which a consumer directly interacts with a service" [64]. Three core themes underpin customers' perceptions of interaction quality: cooperation, confidence and care. The first theme, cooperation, refers to the willingness of the service provider to help users and deliver prompt service $[1,34,59]$. Participants in our qualitative interview referred to this factor as the willingness and promptness of the provider in delivering an mHealth service, as indicated by the 
comments, "Physicians show a sincere interest to solve my problems." The second theme, confidence, measures the degree to which the mHealth platform is considered safe $[1,9,34,59]$. This is an important dimension for inspiring trust and confidence among users, as reflected by the comments; "I feel safe while consulting with physicians" and "physicians' behavior stimulates my confidence to deal with this healthcare platform". The third theme of care reflects the caring and individualized attention of the provider to the patients. It indicates understandability of the user's needs and the ability to provide individualized attention [1, 34, 59]. Comments such as "Physicians understand my specific needs" or "Physicians give me individual care" are evidence of the importance of care in the interaction quality. We believe that these three themes are the salient indicators of interaction quality in the context of our study.

\subsubsection{Information quality}

This study proposes information quality as a critical dimension of service quality: information quality refers to the benefits of the service process or to what a consumer receives as a result of his or her interactions with an mHealth provider [39, 65]. The extant literature has highlighted the importance of perceived information quality in health care in terms of several service benefits which may have varying degrees of importance to the user $[9,66]$. The direct relationship between information quality (information benefits) and service quality is also cited in some healthcare studies [9]. In this study, we have found two key themes of information quality, that is, utilitarian benefits and hedonic benefits of information services [37]. The first theme, utilitarian benefits, refers to the degree to which the mHealth information serves its actual purpose. During the exploratory study, this was frequently discussed as an important parameter, as indicated by the comments; "It serves its purpose very well" or "It is very useful". Most IS 
studies have found that utilitarian benefits of information services (i.e., usefulness) play a critical role in developing a positive attitude toward information technology implementation [56, 57, 67]. The second theme of hedonic benefits refers to the degree to which an mHealth information service arouses positive feelings [37]. Comments such as: "I feel hopeful having service from this platform" or "I believe my future health will improve having this service" highlight the importance of the hedonic benefits of information services. Hedonic benefits have received much attention in recent years as a means of stimulating users' beliefs regarding their perception of service quality $[37,68]$.

\subsection{Scale development}

To develop scales for the service quality subdimensions (i.e., system reliability, system efficiency, system privacy, cooperation, confidence, care, and utilitarian and hedonic benefits of information services) as identified in the qualitative study, items creation and items sorting were undertaken at this stage. The objective of items creation was to ensure content validity by selecting the right items for the construct. On the other hand, the objective of items sorting was to guarantee construct validity by determining the convergence and divergence of items through a sorting process.

\subsubsection{Items creation}

To create an items pool for each construct, at this stage, items were identified using existing instruments, additional items were created through exploratory interviews and, finally, qualitative findings were matched with existing scales to match the construct definitions. To develop scales for system quality, most of the items were adapted from electronic service quality 
studies [61, 37]; however, no valid and reliable scales were identified to measure system privacy and system reliability. New scales thus had to be developed for these constructs. For interaction quality, items were adapted from generic service quality models $[34,11]$ and relevant healthcare studies [8, 9] with context-specific modifications. Finally, in order to develop items for information quality, we adapted items from both electronic [37] and health service quality studies [8]. In selecting items for the different constructs of service quality, Cronbach's alpha coefficient of 0.60 (or composite reliability of 0.7 ) was used as the cut-off value to ensure the reliability of the psychometric properties [69]. Most of the scales in previous instruments tended to follow the format of a 7-point Likert scale (ranging from 'strongly disagree' to 'strongly agree') which was also retained for this study. Finally, item pools were created for the eight service quality subdimensions after a rigorous re-evaluation of the existing items and the addition of new items to adjust the context for the current study. Those items that seemed redundant or confusing were eliminated.

\subsubsection{Items sorting}

The objective of this phase was to assess construct validity by ensuring domain coverage and the reliability of items for each construct. Firstly, domain coverage was assessed with the help of a panel of two judges who sorted each item under the service quality subdimensions by applying the Q-sort procedure. This technique indicated the degree of the "correct" placement of items within different categories of constructs which provided adequate evidence of construct validity by ensuring the convergence and divergence of items. A different set of judges which comprised a user, a student, and a professor was used in the two sorting rounds. Secondly, reliability of the classification scheme was assessed based on the results of two rounds of the Q-sort application. It may be noted that reliability and validity analysis at this phase was predominantly based on 
qualitative analysis rather than on strict quantitative techniques $[69,70]$. Reliability was assessed on the percentage of items placed in the target construct which was $82 \%$. This overall placement ratio also indicates the inter-judge raw agreement scores and associated Kappa scores which averaged 0.86 and 0.83 respectively (see Appendix 2). These findings suggested good reliability coefficients as they compellingly exceeded the threshold level (Kappa > 0.65) [70]. Thus, based on the overall findings, we reduced the items for the various scales to at least three for each. The selection process finally resulted in the following number of items for each pool, a total number of 29 items (see Tables 4 and 5).

Table 4: Items development

\begin{tabular}{|l|l|c|}
\hline Dimension & Subdimensions & No. of items \\
\hline System quality & System reliability & 4 \\
& System efficiency & 4 \\
& System privacy & 3 \\
\hline Interaction quality & Cooperation & 4 \\
& Confidence & 3 \\
& Care & 4 \\
\hline Information quality & Utilitarian benefits & 4 \\
& Hedonic benefits & 3 \\
\hline \multicolumn{2}{|c|}{ Total items } \\
\hline
\end{tabular}

\section{Instrument testing}


We developed the primary version of the questionnaire in English and then translated the measures into the local language (Bangla). The local version was retranslated until a panel of experts agreed that the two versions were reasonably comparable. Before undertaking the pilot study, we conducted a pretest over 15 convenient samples to ensure that the question content, wording, sequence, format and layout, question difficulty, instructions and the range of the scales (5-point vs. 7-point) were appropriate. Upon responses from the pretest, we made contextspecific adjustments to refine the final version of the questionnaire.

In the absence of lists in Bangladesh from which to draw a random sample, area-wise cluster sampling was used to select samples. Both urban and rural areas were selected in a manner so that different socio-economic groups were represented. From each area, firstly, thanas (or suburbs) were randomly selected; streets/villages were then selected from each thana; and finally, residential homes were selected from each street/village. In order to obtain a probability sample, systematic random sampling was applied so that each sample unit/element had an equal chance of being selected. The population was defined as the patients who had had experience of using mHealth services in the past 12 months. After a quick screening question on whether the respondent had used mHealth services in the past 12 months, interviewers proceeded with the survey questions.

The demographic profile of the respondents (see Appendix 1) both in the pilot study and main study represents a diverse cross-section of the population. The respondent group ranged in age from 18 to 62 (mean of 32.7), were $60 \%$ male and $47 \%$ had income less than US\$75 per month. Respondents were employed in a wide range of professions (students, professionals, self- 
employed, academics, farmers, housewives, day laborers, retirees), and had various educational levels (from illiterate to doctoral degrees).

\subsection{Pilot study}

At this stage, a total of 110 responses were collected in January 2010, of which 104 were usable. We conducted the factor analysis using the varimax rotation procedure to assess the initial measurement scale. We used Kaiser-Meyer-Olkin (KMO) and Bartlett's test of sphericity to evaluate the appropriateness of the factor analysis. The former one ensured the overall measure of sampling adequacy as it was $0.780(>0.50)$ and the latter one provided support for the validity of the instrument as it was 1855.055, $\mathrm{df}=276$, significant at $\mathrm{p}=0.000$. Eight factors with eigenvalues greater than 1 were extracted and, after rotation, they were $2.886,2.844,2.747$, $2.659,2.437,2.312,2.042$, and 1.689. The sums of squared loadings from the eight components had the cumulative value of $81.737 \%$ in explaining the total variance in data. 
Table 5: Results of exploratory factor analysis in the pilot study

\begin{tabular}{|c|c|c|c|c|c|c|c|c|c|}
\hline Code & Items & $\begin{array}{c}\text { Factor } \\
1 \\
\end{array}$ & $\begin{array}{c}\text { Factor } \\
2 \\
\end{array}$ & $\begin{array}{c}\text { Factor } \\
3 \\
\end{array}$ & $\begin{array}{c}\text { Factor } \\
4 \\
\end{array}$ & $\begin{array}{c}\text { Factor } \\
5 \\
\end{array}$ & $\begin{array}{c}\text { Factor } \\
6 \\
\end{array}$ & $\begin{array}{c}\text { Factor } \\
7 \\
\end{array}$ & $\begin{array}{c}\text { Factor } \\
8 \\
\end{array}$ \\
\hline
\end{tabular}

*Item scores not reported due to low factor loadings $(<0.40)$ or similar loadings on more than one factor.

Throughout the process of exploratory factor analysis, items were deleted that did not load properly on a particular factor $(<0.40)$ or had cross loadings (see Table 5). In this way, SQ4, SQ8, SQ11, SQ15, SQ19, and SQ26 were deleted. Reliability analysis (i.e., Cronbach's alpha) of the extracted eight factors was then conducted which compellingly exceeded the cut-off value of 0.70. Further scale refinement was done by examining corrected item-total correlation to improve the reliability. As a result, SQ18 was deleted. In summary, the initial instrument was refined by removing SQ4, SQ8, SQ11, SQ15, SQ18, SQ19 and SQ26.

Table 6: Results of exploratory factor analysis of the refined scale in the pilot study 


\begin{tabular}{|c|c|c|c|c|c|c|}
\hline Factor & Items & Loadings & $\begin{array}{l}\text { Item total } \\
\text { correlation }\end{array}$ & Eigenvalue & $\begin{array}{l}\text { Cumulative } \\
\text { variation }\end{array}$ & Cronbach's alpha \\
\hline System reliability & $\begin{array}{l}\text { SQ1 } \\
\text { SQ2 } \\
\text { SQ3 }\end{array}$ & $\begin{array}{l}0.702 \\
0.909 \\
0.854\end{array}$ & $\begin{array}{l}0.582 \\
0.801 \\
0.706\end{array}$ & 2.889 & 12.563 & 0.831 \\
\hline System efficiency & $\begin{array}{l}\text { SQ5 } \\
\text { SQ6 } \\
\text { SQ7 }\end{array}$ & $\begin{array}{l}0.850 \\
0.875 \\
0.827\end{array}$ & $\begin{array}{l}0.787 \\
0.890 \\
0.775\end{array}$ & 2.844 & 24.927 & 0.908 \\
\hline System privacy & $\begin{array}{c}\text { SQ9 } \\
\text { SQ10 }\end{array}$ & $\begin{array}{l}0.951 \\
0.932 \\
\end{array}$ & $\begin{array}{l}0.903 \\
0.881 \\
\end{array}$ & 2.744 & 36.856 & 0.924 \\
\hline Cooperation & $\begin{array}{l}\text { SQ12 } \\
\text { SQ13 } \\
\text { SQ14 }\end{array}$ & $\begin{array}{l}0.865 \\
0.901 \\
0.896\end{array}$ & $\begin{array}{l}0.844 \\
0.897 \\
0.870\end{array}$ & 2.587 & 48.104 & 0.937 \\
\hline Confidence & $\begin{array}{l}\text { SQ16 } \\
\text { SQ17 }\end{array}$ & $\begin{array}{l}0.728 \\
0.768\end{array}$ & $\begin{array}{l}0.544 \\
0.606\end{array}$ & 2.299 & 58.099 & 0.716 \\
\hline Care & $\begin{array}{l}\text { SQ20 } \\
\text { SQ21 } \\
\text { SQ22 }\end{array}$ & $\begin{array}{l}0.798 \\
0.817 \\
0.766\end{array}$ & $\begin{array}{l}0.712 \\
0.698 \\
0.752\end{array}$ & 2.297 & 68.085 & 0.850 \\
\hline Utilitarian benefits & $\begin{array}{l}\text { SQ23 } \\
\text { SQ24 } \\
\text { SQ25 }\end{array}$ & $\begin{array}{l}0.816 \\
0.753 \\
0.654\end{array}$ & $\begin{array}{l}0.609 \\
0.534 \\
0.577\end{array}$ & 2.036 & 76.938 & 0.746 \\
\hline Hedonic benefits & $\begin{array}{l}\text { SQ27 } \\
\text { SQ28 } \\
\text { SQ29 }\end{array}$ & $\begin{array}{l}0.888 \\
0.858 \\
0.854\end{array}$ & $\begin{array}{l}0.862 \\
0.830 \\
0.862\end{array}$ & 1.483 & 83.387 & 0.928 \\
\hline
\end{tabular}

The remaining 22 items were retained for the next run of factor analysis. As shown in Table 6, an exploratory factor analysis with a varimax rotation yielded eight factors based on an eigenvalue cut-off of 1 . The refined model explained $83.387 \%$ of the cumulative variance. The remaining items were split into eight factors: system reliability, system efficiency, system privacy, cooperation, confidence, care, and utilitarian and hedonic benefits of information services. Both the KMO (0.76) and the Bartlett's test of sphericity $(\mathrm{p}=0.000)$ were significant. The minimum Cronbach's alpha was 0.716 for confidence, satisfying the minimum requirement of 0.70 . The minimum corrected-item-total correlation was 0.534 , exceeding the cut-off value of 0.40 which was recommended by Straub et al. [69]. Thus, the reliability of the refined model was established. 


\subsection{Conceptual model: A hierarchical, multidimensional service quality model}

Based on the qualitative findings, supporting literature and the factor structure of service quality in the exploratory study, as shown in Figure 1, a conceptual model of service quality is proposed to measure the dimensions, subdimensions and their association with service satisfaction and continuance intentions in a nomological network. We specify service quality as a hierarchical, reflective model which is comprised of three primary dimensions (i.e., system quality, interaction quality and information quality) and eight subdimensions (i.e., system reliability, system efficiency, system privacy, cooperation, confidence, care, and utilitarian and hedonic benefits of information services). Thus, based on the decision criteria of Jarvis et al. [71], Petter et al. [75] and Polites et al. [104], we argue that mHealth service quality is a higher-order, multidimensional, reflective construct which is discussed in further detail below.

Firstly, the mHealth service quality model is a reflective model because the theoretical direction of causality is from construct to items (see Figure 1). The model indicates that measures are manifestations of constructs, that is, all the measures under a construct share a common theme [71, 75, 104]. In our study, for example, systems privacy was manifested by two measures: "It protects my personal information" and "It does not share information with others". Aligned with the established decision criteria, these two measures are interchangeable and share one theme. Secondly, the findings of the exploratory study confirmed the reflective perspective because the correlation between measures under a construct was highly positive [72] and internal consistency was significant [71]. Thirdly, the findings provided evidence for the unidimensionality of the reflective constructs which allowed the elimination of some measures during the scale refinement stage to improve construct validity without affecting content validity. Overall, the 
extant literature on service quality modeling $[10,37]$ and measurement model specifications $[60$, 73, 74, 75, 76, 104, 105] supports this view of hierarchical, reflective modeling. This hierarchical, reflective, multidimensional model is also known as a superordinate model [77, 104], a principal factor model [75] or a common latent construct model [78]. Table 7 synthesizes the justifications for specifying the research model as a reflective model based on the findings of the exploratory study.

Table 7: Nature of the reflective service quality model

\begin{tabular}{|c|c|}
\hline Reflective mHealth service quality model* & Reasons for a reflective model \\
\hline $\begin{array}{l}Y_{i}=\beta_{i 1} X_{1}+\varepsilon_{i} \\
\text { where, } \\
Y_{i}=\text { the } i^{\text {th }} \text { indicator } \\
\beta_{i 1}=\text { coefficient represents the effect of the latent } \\
\text { variable on the indicator } \\
X_{1}=\text { latent variable (e.g., system reliability) } \\
\varepsilon_{i}=\text { measurement error for indicator } i\end{array}$ & $\begin{array}{l}\text { - All the constructs are reflective } \\
\text { - Direction of causality is from construct to items } \\
\text { - Indicators are manifestations of the construct } \\
\text { - Changes in the construct cause changes in the } \\
\text { indicators } \\
\text { - Indicators are interchangeable, having a common } \\
\text { theme and dropping of an indicator should not change } \\
\text { the conceptual domain of the construct } \\
\text { - Indicators are expected to covary with each other } \\
\text { - Indicators are required to have the same antecedents } \\
\text { and consequences (i.e., same nomological network) }\end{array}$ \\
\hline
\end{tabular}

Thus, to assess the nomological validity of the higher-order, reflective mHealth service quality model and to measure its association with satisfaction and continuance intentions, we posit that:

H1: Service quality has a positive impact on user satisfaction.

H2: Service quality has an indirect, positive impact on continuance through satisfaction.

H3: Service quality has a direct, positive impact on continuance intentions. 


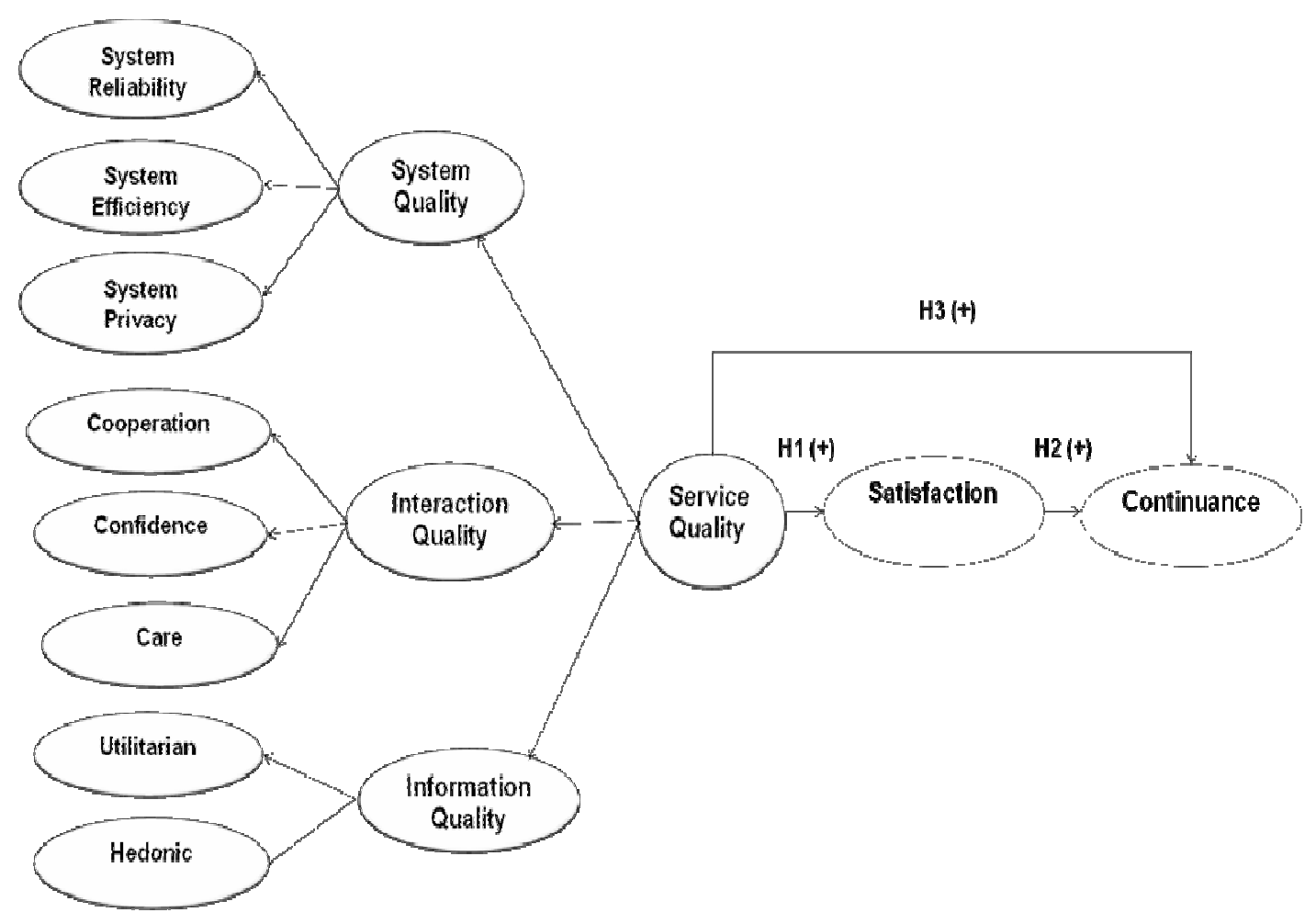

Figure 1: Service Quality Model for mHealth

\subsection{Confirmatory study}

Although we validated the items and the factor structure of the proposed service quality scale in the pilot study, it provided little evidence of convergent, discriminant, nomological and predictive validity. Thus, confirmatory factor analysis (CFA) was used to rigorously assess the refined instrument over a larger group of mHealth users. As such, in March 2010, a total of 305 surveys were completed using the same sampling procedure as used in the pilot study, of which $283(93 \%)$ were usable.

In order to estimate the hierarchical mHealth service quality model, the study applied component-based structural equation modeling (SEM) or partial least squares (PLS) path modeling for two reasons. Firstly, the study applied PLS because higher-order models using 
covariance-based SEM (CBSEM) are susceptible to empirical under-identification due to a high degree of factor correlations (very close to 0 or 1 ) which can lead to improper solutions $[73,76]$. Secondly, the study applied PLS because CBSEM typically results in positively-biased model fit indices in the context of hierarchical models as the degrees of freedom increase with the increasing number of indicators and latent variables $[107,110]$. Thirdly, the study applied PLS because the study's research model is complex as it contains 14 constructs (i.e., 8 first-order +3 second-order +1 third-order +2 outcome constructs) and more than 50 items ( 22 items at firstorder, 22 items at second-order and 22 items at third-order levels). In this particular case, using CBSEM causes difficulties in handling such larger models "due to the algorithmic nature requiring inverting of matrices" [73, p. 661]. Therefore, the study favored PLS path modeling to estimate this large complex model because it can remove the uncertainty of inadmissible solutions using its flexible assumptions both in exploratory and confirmatory settings [108, 109]. In a similar spirit, Chin [73, p. 660], stated that "[i]t should not be construed that PLS is not appropriate in a confirmatory sense nor in well researched domains". Thus, the application of PLS in our study successfully averted the limitations of CBSEM in estimating the hierarchical model with regard to distributional properties, measurement level, model complexity, identification and factor indeterminacy [76, 80, 81]. PLS also helped in achieving more theoretical parsimony and less model complexity by estimating the higher-order model.

In estimating the higher-order reflective model using PLS path modeling, the study repeatedly used the manifest variables for the first-order, the second-order and, finally, for the third-order loadings [82, 83, 84, 85]. According to Wetzels et al. [76], "[t]his approach also allows us to derive the (indirect) effects of lower-order constructs, or dimensions, on outcomes of the higher- 
order construct". Specifically, the study applied PLS Graph 3.0 to estimate the parameters in the outer and inner model with a path weighting scheme for the inside approximation $[76,84,86]$. The study also applied nonparametric bootstrapping [76, 81, 84, 87] with 500 replications to obtain the standard errors of the estimates. Thus, the third-order construct, service quality, was estimated by all of the indicators of the second-order constructs (i.e., system quality, interaction quality and information quality) and, in turn, the second-order constructs were directly estimated by the indicators of the corresponding first-order constructs (see Appendix 3: Equations for hierarchical modeling).

\subsubsection{Assessment of the first-order scale}

As shown in Table 8, the results of the CFA show that all item loadings of the first-order model were larger than 0.7 and significant at $\mathrm{p}<0.01$. All average variance extracted (AVE) and composite reliabilities (CRs) exceeded the cut-off values of 0.5 and 0.8 respectively $[73,81,86]$. The lowest CR (0.879) and AVE (0.707) were for utilitarian benefits; however, all those values compellingly exceeded their recommended threshold values. Thus, we ensured convergent validity because all the indicators loaded much higher on their hypothesized factor than on other factors (their own loading was higher than cross loadings). In addition, as shown in Table 9, we calculated the square root of the AVE that exceeded the intercorrelations of the construct with the other constructs, which ensured discriminant validity $[73,81,88]$. Thus, the measurement model was considered satisfactory with evidence of adequate reliability, convergent validity and discriminant validity, and was therefore employed for testing the hypotheses and proving the research model. 


\begin{tabular}{|c|c|c|c|c|c|c|c|c|c|c|}
\hline \multicolumn{11}{|c|}{ Table 8: Psychometric properties of the hierarchical service quality scale* } \\
\hline \multicolumn{5}{|c|}{ First-order Constructs } & \multicolumn{3}{|c|}{ Second-order Constructs } & \multicolumn{3}{|c|}{ Third-order Construct } \\
\hline Constructs & Items & Loadings & $\mathrm{CR}$ & AVE & Constructs & $\mathrm{CR}$ & AVE & Construct & $\mathrm{CR}$ & AVE \\
\hline $\begin{array}{l}\text { System } \\
\text { reliability }\end{array}$ & 3 & $0.890-0.937$ & 0.942 & 0.844 & \multirow{3}{*}{$\begin{array}{l}\text { System } \\
\text { quality }\end{array}$} & \multirow[t]{3}{*}{0.904} & \multirow[t]{3}{*}{0.544} & \multirow{10}{*}{$\begin{array}{l}\text { Service } \\
\text { quality }\end{array}$} & \multirow{10}{*}{0.962} & \multirow{10}{*}{0.538} \\
\hline $\begin{array}{l}\text { System } \\
\text { efficiency }\end{array}$ & 3 & $0.934-0.937$ & 0.960 & 0.889 & & & & & & \\
\hline $\begin{array}{l}\text { System } \\
\text { privacy }\end{array}$ & 2 & $0.976-0.977$ & 0.976 & 0.953 & & & & & & \\
\hline Cooperation & 3 & $0.916-0.927$ & 0.944 & 0.849 & \multirow{3}{*}{$\begin{array}{l}\text { Interaction } \\
\text { quality }\end{array}$} & \multirow{3}{*}{0.938} & \multirow{3}{*}{0.655} & & & \\
\hline Confidence & 2 & $0.935-0.941$ & 0.936 & 0.880 & & & & & & \\
\hline Care & 3 & $0.881-0.947$ & 0.946 & 0.854 & & & & & & \\
\hline $\begin{array}{l}\text { Utilitarian } \\
\text { benefits }\end{array}$ & 3 & $0.834-0.845$ & 0.879 & 0.707 & \multirow{2}{*}{$\begin{array}{l}\text { Information } \\
\text { quality }\end{array}$} & \multirow[t]{2}{*}{0.940} & \multirow[t]{2}{*}{0.724} & & & \\
\hline $\begin{array}{l}\text { Hedonic } \\
\text { benefits }\end{array}$ & 3 & $0.945-0.961$ & 0.967 & 0.907 & & & & & & \\
\hline Satisfaction & 4 & $0.942-0.953$ & 0.973 & 0.901 & & & & & & \\
\hline $\begin{array}{l}\text { Continuance } \\
\text { intentions }\end{array}$ & 3 & $0.928-0.972$ & 0.964 & 0.900 & & & & & & \\
\hline
\end{tabular}

\begin{tabular}{|l|l|l|l|l|l|l|l|l|l|l|l|l|}
\hline \multicolumn{7}{|c|}{ Table 9: Mean, standard deviation (SD) and correlations of first-order constructs* } \\
\hline Construct & Mean & $\boldsymbol{S D}$ & $\boldsymbol{S R}$ & $\boldsymbol{S E}$ & $\boldsymbol{S P}$ & $\boldsymbol{R} \boldsymbol{E}$ & $\boldsymbol{A S}$ & $\boldsymbol{E} \boldsymbol{F}$ & $\boldsymbol{F B}$ & $\boldsymbol{E B}$ & $\boldsymbol{S A T}$ & $\boldsymbol{C O N}$ \\
\hline $\begin{array}{l}\text { System } \\
\text { reliability }\end{array}$ & 5.673 & 1.144 & 0.919 & & & & & & & & & \\
\hline $\begin{array}{l}\text { System } \\
\text { efficiency }\end{array}$ & 5.500 & 1.186 & 0.460 & 0.943 & & & & & & & & \\
\hline System privacy & 5.315 & 1.240 & 0.278 & 0.451 & 0.976 & & & & & & & \\
\hline Cooperation & 5.993 & 1.110 & 0.549 & 0.583 & 0.310 & 0.921 & & & & & & \\
\hline Confidence & 5.575 & 1.257 & 0.452 & 0.590 & 0.470 & 0.597 & 0.938 & & & & & \\
\hline Care & 5.820 & 1.149 & 0.442 & 0.551 & 0.429 & 0.632 & 0.695 & 0.924 & & & & \\
\hline $\begin{array}{l}\text { Utilitarian } \\
\text { benefits }\end{array}$ & 5.730 & 1.053 & 0.523 & 0.630 & 0.438 & 0.639 & 0.765 & 0.734 & 0.841 & & & \\
\hline $\begin{array}{l}\text { Hedonic } \\
\text { benefits }\end{array}$ & 5.550 & 1.249 & 0.556 & 0.612 & 0.402 & 0.646 & 0.402 & 0.724 & 0.789 & 0.952 & & \\
\hline Satisfaction & 5.555 & 1.087 & 0.558 & 0.533 & 0.381 & 0.591 & 0.695 & 0.659 & 0.729 & 0.714 & 0.949 & \\
\hline $\begin{array}{l}\text { Continuance } \\
\text { intentions }\end{array}$ & 5.524 & 1.313 & 0.461 & 0.499 & 0.355 & 0.544 & 0.609 & 0.567 & 0.691 & 0.679 & 0.728 & 0.948 \\
\hline & $* 6$ (Discriminant validity: square root of AVE on the diagonal > correlation coefficients) & \\
\hline
\end{tabular}




\subsubsection{Assessment of the higher-order scale}

This study also estimated the parameters of the higher-order scale as shown in Table 8 . The results showed that the CRs and AVE of the second- and third-order scales were greater than 0.80 and 0.50 respectively, which provided evidence of reliable higher-order measures. The results confirmed that the third-order construct, service quality, had a strong association with the second-order constructs of system quality $(\beta=0.880)$, interaction quality $(\beta=0.943)$, and information quality $(\beta=0.934)$ which explained $78 \%, 89 \%$ and $87 \%$ of overall quality variance

respectively (see Appendix 4). The results also confirmed that the second-order constructs had a strong association with their corresponding first-order constructs. For example, system quality was reflected by system reliability $(\beta=0.770)$, system efficiency $(\beta=0.869)$ and system privacy $(\beta=0.662)$, of which system efficiency reflected the highest variance of system quality. All path coefficients from service quality to second-order and third-order components were significant at $\mathrm{p}<0.01$ (see Appendix 5). Thus, we found that the 22 items, grouped into eight factors, could be used to measure the overall service quality of mHealth services.

\subsubsection{Assessment of the nomological and predictive validity}

We assessed the nomological validity of the service quality scale in mHealth services by examining its relationship with satisfaction and continuance intentions. In order to assess such validity, we used previously published multi-item scales of satisfaction [89] and continuance intentions [58]. The AVE and CRs of these constructs compellingly exceeded their cut-off values (see Table 8). The results gave a standardized beta of $0.779,0.449$ and 0.358 respectively from service quality to satisfaction, satisfaction to continuance intentions, and service quality to continuance intentions (see Table 10). All these path coefficients were significant at $\mathrm{p}<0.001$, 
which proved $\mathrm{H} 1, \mathrm{H} 2$ and $\mathrm{H} 3$ (see Appendix 5). In addition, this study obtained $R^{2}$ (the coefficient of determination) of 0.61 for satisfaction and 0.58 for continuance intentions, which were significantly large $(>0.30)$ according to the measure of explained variance defined for $R^{2}$ [69]. These results confirmed the impact of service quality on satisfaction and continuance intentions, thereby ensuring nomological validity (see Figure 2). Furthermore, this study used Stone-Geisser's $Q^{2}$ to test predictive validity. To ensure high predictive validity, Stone-Geisser's $Q^{2}$ should exceed zero [73, 81]. Using the cross-validated redundancy approach, this study obtained $Q^{2}$ of 0.54 for satisfaction and 0.51 for continuance intentions which demonstrated the predictive validity of the higher-order mHealth service quality scale (see Figure 2).

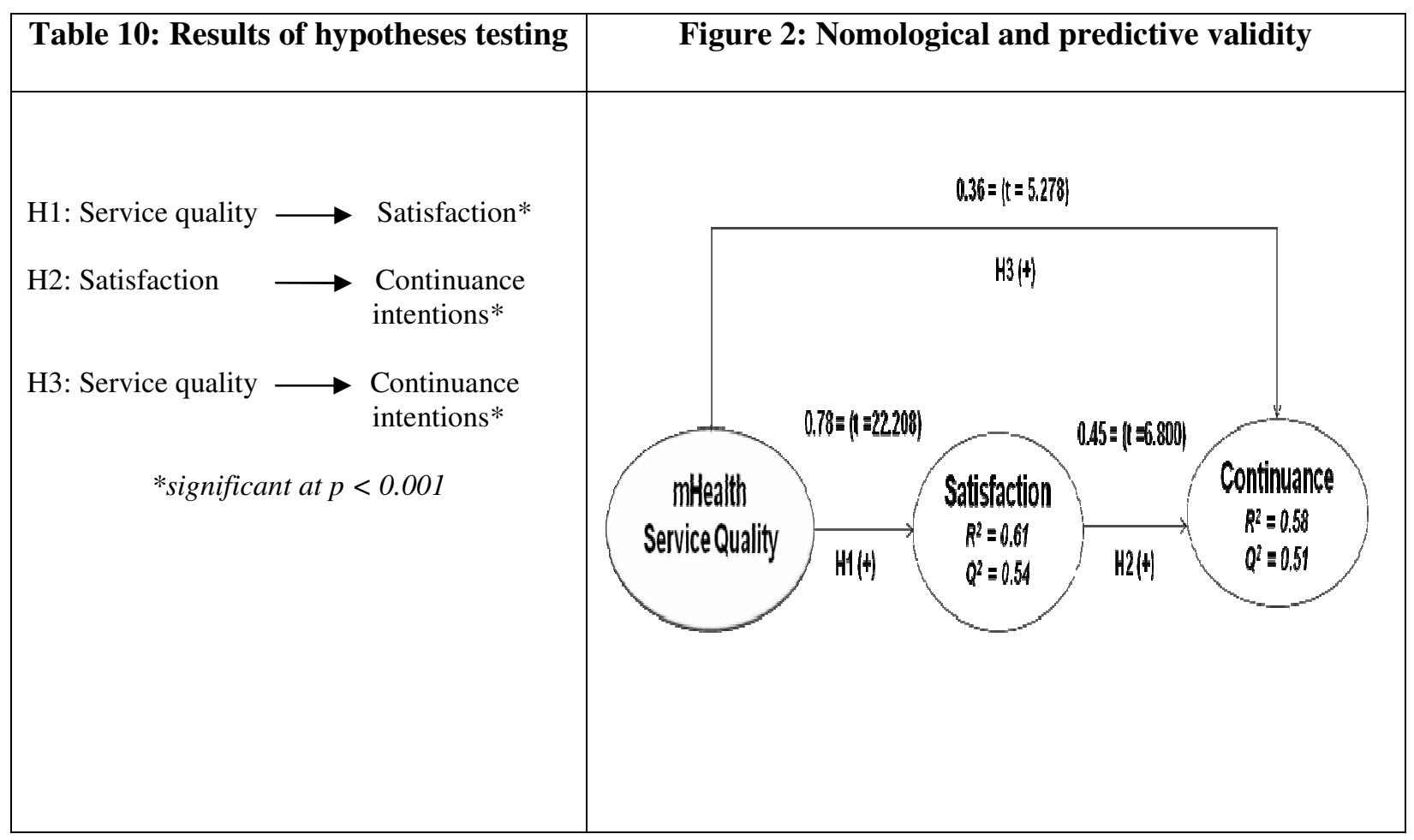




\subsubsection{Assessment of the overall parameters}

In order to assess the robustness of the hierarchical service quality scale, firstly, we estimated the power $(1-\beta)$ of the model in order to assess its ability to reject a false null hypothesis $\left(\mathrm{H}_{0}\right)$ [94]. In this study, the power of the overall scale (model) was 0.99 which compellingly exceeded the 0.80 cut-off value. This high power $(>0.80)$ indicated that the results of the hypotheses testing were valid and the relationships were significant. Secondly, this study estimated the global fit index (GoF) to assess the global validity of the service quality scale [84]. The GoF refers to the geometric mean of the average communality and average $R^{2}$ for all endogenous constructs. According to Wetzels et al. [76], the GoF value ranges between small $(\mathrm{GoF}=0.1)$, medium $(\mathrm{GoF}=0.25)$ and large $(\mathrm{GoF}=0.36)$. This study obtained a GoF value of 0.775 for the overall service quality scale, which exceeded the cut-off value of 0.36 for large effect sizes of $R^{2}$ [94]. Thus, this allows us to conclude that the mHealth service quality scale has a better prediction power, which adequately validates the research model globally.

\section{Discussion}

\subsection{Summary of findings}

The purpose of this paper was to develop and validate an instrument for measuring service quality in mHealth services. Since the development of a reliable and valid scale is a fundamental goal of scientific exploration, the higher-order, mHealth instrument put forward in this study makes an important contribution to theory, method and practice. Multiple rounds of empirical validation supported our formulation of a third-order, hierarchical, reflective service quality scale. It also offers interesting insights into how service quality is reflected in the ultimate users' 
perceptions. The findings suggest that consumers of mHealth services base their perceptions of service quality on three primary dimensions: system quality, interaction quality and information quality. These primary dimensions, in turn, are reflected by eight underlying subdimensions. These subdimensions are system reliability, system efficiency, system privacy, cooperation, confidence, care, and utilitarian and hedonic benefits of information services. The hierarchical nature of the scale suggests that the third-order construct, service quality, is reflected by three second-order constructs, which in turn are reflected by eight first-order constructs. In developing the hierarchical, reflective scale, we applied the approach of repeated indicators [85] using PLS path modeling which confirmed adequate psychometric properties. We also confirmed the nomological validity of the integrated model by identifying the strong impact of service quality on satisfaction $\left(R^{2}=0.608\right)$ and continuance intentions $\left(R^{2}=0.581\right)$, in which satisfaction was recognized as a strong mediator $[90,91,92]$.

\subsection{Implications for theory:}

This study extends service quality research by developing and validating a higher-order mHealth service quality model on three primary dimensions (i.e., system quality, interaction quality and outcome quality) and eight subdimensions (system reliability, system efficiency, system privacy, cooperation, confidence, care, and utilitarian and hedonic benefits of information services). By encompassing the combined explanatory power of each component, the mHealth quality model advances service quality theory in IS research while presenting a parsimonious structure. According to Whetten [102, p. 493], "[t]his approach adds the qualities of completeness and thoroughness to theoretical work". Specifically, the study contributes in several ways to service quality research. Firstly, it defines all the constructs and their associated measurement 
instruments against the backdrop of service quality in the mHealth context. Secondly, it identifies a comprehensive, yet parsimonious, set of items that help predict the quality of an emerging IT artifact (i.e., mHealth) with its impact on patient satisfaction and continuance intentions. Thirdly, it explores the characteristics specific to the mobile electronic platform that provide a solution to new and difficult service delivery challenges. Fourthly, the study frames continuance intentions as a critical outcome of service quality, which has not been investigated before in IT service quality research. Finally, from an analytical point of view, this study models service quality for the first time as a third-order, reflective model using PLS, which clearly provides new insights and clarifications for component based structural equation modeling.

\subsection{Implications for practice}

The implications of this research are highly relevant to the decision makers of mHealth platforms who are offering such ubiquitous health services. The findings suggest that customers evaluate service quality at an overall level, a dimensional level (system quality, interaction quality and information quality) and at subdimensional level (system reliability, system efficiency, system privacy, cooperation, confidence, care, and utilitarian and hedonic benefits of information services). These findings improve the understanding of managers on how customers evaluate service quality in the context of mHealth services. In particular, such findings suggest that managers should focus on improving the quality of the services they provide across the three primary dimensions which can be achieved by the eight subdimensions. For instance, perceptions of system quality could be improved by increasing the reliability, efficiency and privacy of the service system. Likewise, interaction quality could be improved by serving customers with a prompt response, adequate knowledge and proper attention. Also, information quality could be 
enhanced by updating customers on the utilitarian and hedonic benefits of information services (e.g., convenience, cost effectiveness, usefulness, etc.).

The proposed framework paves the way for conducting the integrated analysis and design of service delivery systems for mobile health services. For managers of mHealth services, it underscores the point that having only a good technological platform (e.g., information systems and wireless network) is not sufficient to deliver the desired levels of service quality. Thus, they need to address in a coordinated manner, the system quality, the interaction quality and information quality when designing service delivery systems [63]. This framework also provides a useful road map for making interventions in the service delivery systems targeting the improvement of a particular quality dimension at different levels [21]. It highlights that quality issues arising in different parts of the service delivery system have different natures, for example, system quality deals with 'human-technology interaction', interaction quality deals with 'interpersonal interaction', and information quality deals with 'service benefits' evaluation' derived from the service delivery platform.

The model developed in this study offers managers an understanding of how individual service quality dimension and overall service quality interact in predicting satisfaction and continuance intentions. In fact, this relationship is one of the critical challenges in identifying and replicating the best mHealth practices around the world $[1,2,15]$. It is widely believed that findings on such an association will facilitate the scalability of this new healthcare paradigm. It will also help decision makers to consider mHealth implementation as a success when a significant number of users move beyond the initial adoption stage and use this service on a continued basis. The 
findings of the study suggest that overall service quality is a critical predictor of user satisfaction (explaining $60 \%$ of satisfaction variance) and continuance intentions (explaining 58\% of continuance variance). These findings suggest that decision makers should consider 'service quality' as an important strategic objective to ensure positive satisfaction and continuance intentions. Overall, the mHealth service quality model proposed in this study can help providers achieve patronage for organizations, better health outcomes for patients and, above all, an improved quality of life for the community.

\section{Limitations and future research directions}

Several limitations are worth noting. Firstly, this research was conducted within the specific domain of mHealth services and in only one country. Although service quality research by its nature is context specific, replications in other contexts would increase the confidence in the research model. Secondly, data were collected under cross-sectional design so the study contains the typical limitations associated with this kind of research methodology. For example, the model represents the static nature of service evaluation and the findings are confined to a single point of time. To gain a deeper understanding, a longitudinal study could be used to evaluate users' perceptions on mHealth service quality over time. Future research could also explore the impact of contextual factors, such as, demographic variables (income, education, gender, etc.) and situational constructs (usage frequency, cost, etc.), on the research model. Additional research is needed to develop a refined understanding of the nature of the relationships proposed in the integrated model. It would be useful for future research to estimate hierarchical models with both reflective-formative parameters by applying PLS path modeling.

\section{Conclusion}


The instrument developed in this study can be used to monitor and improve service quality of an innovative IT artifact, that is, mHealth services. The scale development process has successfully integrated the suggestions of seminal instrument development studies $[69,70,79,93,106]$ and extended their contribution by introducing sophisticated reliability and validity techniques (see Appendix 6). The result is a parsimonious 22 item-instrument, grouped into eight scales, with a high degree of reliability and validity. Although developed in the context of mHealth, this instrument may be applied to assess the quality of any mobile platform-driven services. The overall findings of the study provide critical insights for academics and practitioners on hierarchical scale development and validation procedures.

\section{Acknowledgements}

This research was funded by the Asia Pacific Ubiquitous Healthcare Research Centre (APuHC), Australia. The authors appreciate and gratefully acknowledge the guidance and constructive comments of Wynne W. Chin of the University of Houston. The authors also thank the data collection team of World Health Organization (WHO) Global mHealth Assessment Project (Bangladesh Chapter) comprising Benzir Shaon, Saida Mona, Waheduzzaman Adnan, Ismat Ara, and Shafayet Ullah for their invaluable help.

\section{References}

[1] S. Akter, J. D'Ambra, P. Ray, User perceived services quality of mHealth services in developing countries, in the Proceedings of the Eighteen European Conference on Information Systems, (2010) Pretoria, South Africa. 
[2] United Nations foundation \& Vodafone foundation. mHealth for Development: The opportunity of mobile technology for healthcare in developing world (2009), Available at: http:// www.vitalwaveconsulting.com/insights/ mHealth.htm [Accessed September 03, 2010]

[3] P. Ahluwalia, U. Varshney, Composite quality of service and decision making perspectives in wireless networks, Decision Support Systems 46 (2), 2009, pp. 542-551

[4] S. Chatterjee, S. Chakraborty, S. Sarker, S. Sarker, F.Y. Lau, Examining the success factors for mobile work in healthcare: a deductive study, Decision Support Systems 46 (3), 2009, pp. 620-633.

[5] I. Junglas, C. Abraham, R.T. Watson, Task-technology fit for mobile locatable information systems, Decision Support Systems 45 (4), 2008, pp. 1046-1057.

[6] S. Sneha, U. Varshney, Enabling ubiquitous patient monitoring: model, decision protocols, opportunities and challenges, Decision Support Systems 46 (3), 2009, pp. 606-619.

[7] U. Varshney Pervasive Healthcare: Applications, Challenges and Wireless Solutions, Communications of the Association for Information Systems 16(3), 2005, pp. 57-72.

[8] T.S. Dagger, J.C. Sweeney, L.W. Johnson, A Hierarchical Model of Health Service Quality: Scale Development and Investigation of an Integrated Model. Journal of Service Research 10(2) (2007) 123-142.

[9] S.S. Andaleeb, Service quality perceptions and patient satisfaction: a study of hospitals in a developing country. Social Science \& Medicine 52(9), 2001, pp. 1359-1370.

[10] T.R. Rust, R. L. Oliver, Service Quality: Insights and Managerial Implications from the Frontier, in Service Quality: New Directions in Theory and Practice, Roland T. Rust and Richard L. Oliver, eds. Thousand Oaks, CA: Sage, 1-19,1994.

[11] M. K. Brady, J.J. Cronin, Some New Thoughts on Conceptualizing Perceived Service Quality: A Hierarchical Approach, Journal of Marketing 65 (July), 2001, 34-49.

[12] E. Babakus, W.B. Gregory. An Empirical As.sessment of the SERVQUAL Scale, Journal of Business Research 24 (3), 1992, pp. 253-68

[13] J.M. Carman, Consumer Perceptions of Service Quality: An Assessment of the SERVQUAL Dimensions, Journal of Retailing 66 (1), 1990, pp. 33-55.

[14] P.A. Dabholkar, D.I. Thorpe, J.O. Rentz, A Measure of Service Quality for Retail Stores:Scale Development and Validation, Journal of the Academy of Marketing Science 24 (1) (1996) 3-16.

[15] S. Akter \& P. Ray, mHealth-an ultimate platform to serve the unserved. IMIA Yearbook of Medical Informatics (2010) 75-81.

[16] Vita wave consulting, mHealth in the developing world-a landscape analysis (2010) Available at www.vitalwaveconsulting.com

[17] International Telecommunication Union, ITU mobile health initiative (2010) available at http://www.itu.int/ITU-D/connect/flagship_initiatives/mHealth.html

[18] B. Kaplan, S. Litewka, Ethical challenges of telemedicine and telehealth, Cambridge Quarterly of Healthcare Ethics 17, 2008, pp. 401-416.

[19] M.C. Angst, R. Agarwal, Adoption of electronic health records in the presence of privacy concerns: the elaborate likelihood model and individual persuasion, MIS Quarterly 33(2), 2009, pp. 339-370

[20] G. Ivatury, J. Moore, A. Bloch, A Doctor in Your Pocket: Health Hotlines in Developing Countries, Innovations: Technology, Governance, Globalization 4(1), 2009, pp.119 $\square 153$.

[21] R.R. Nelson, P.A. Todd, B.H. Wixom, Antecedents of information and systems quality: an empirical examination within the context of data warehousing 21 (4), 2005, pp.199-235

[22] P. Mechael, The case for mHealth in developing countries, Innovations: Technology, Governance, Globalization 4(1), 2009, pp.103-118,

[23] E. Ammenworth, A. Buchauer, B. Bludau, R. Haux, Mobile information and communication tools in the hospital, International Journal of Medical Informatics (57), 2000.

[24] N. Maglaveras, V. Koutkias, I. Chouvarda, D.G. Goulis, A. Avramides, D. Adamidis, E.A. ELouridas, E.A. Balas, Home care delivery through the mobile telecommunications platform: the citizen health system (CHS) perspective, International Journal of Medical Informatics 68 (1-3), 2002, pp. 99-111.

[25] K. Hameed, The application of mobile computing and technology to health care services, Telematics and Informatics 20, 2003, 99-106

[26] U. Varshney, Using wireless technologies in healthcare, Int. J. Mobile Communications 4(3), 2006, pp.354-368

[27] W.Y. Jen, C.C. Chao, M.C. Hung, Y.C. Li, Y.P. Chi, Mobile information and communication in the hospital outpatient service, international journal of medical informatics 76 , 2007,pp. 565-574 
[28] U. Varshney, A middleware framework for managing transactions in group oriented mobile commerce services, Decision Support Systems 46 (1), 2008, pp. 356-365.

[29] K. Patrick, W.G. Griswold, F. Raab, S.S. Intille, Health and the mobile phone, American Journal of Preventive Medicine 35(2), 2008.

[30] A. Lorenz, R. Opperman, Mobile health monitoring for the elderly: designing for diversity, Pervasive and Mobile computing, 5 (5), 2009, pp. 478-495

[31] D. Han, M. Lee, S. Park, THE-MUSS: Mobile u-health service system, computer methods and programs in biomedicine 9 7, 2010, pp. 178-188

[32] V. A. Zeithaml, Defining and Relating Price, Perceived Quality, and Perceived Value, Cambridge, MA: Marketing Science Institute, Report No, 87-101, 1987.

[33] C. Gronroos, Strategic Management and Markeling in the Service Sector. Helsingfors; Swedish School of Economics and Business Administration, 1982.

[34] A. Parasuraman, V.A. Zeithaml, L.L. Berry, SERVQUAL: A Multiple-Item Scale for Measuring Consumer Perceptions of Service Quality. Journal of Retailing 64(1), 1988, pp.5-6.

[35] J.J. Cronin. S.A. Taylor, Measuring Service Quality: A Reexamination and Extension, Journal of Marketing 56 (July), 1992, pp.55-68.

[36] RACE (1994) UMTS System Structure Document, Issue 1.0. RACE 2066 Mobile Networks (MONET), CEC Deliverable No:R2066/LMF/GA1/DS/P/052/b1

[37] M. Fassnacht, I. Koese, Quality of Electronic Services: Conceptualizing and Testing a Hierarchical Model, Journal of Service Research 9 (19), 2006, pp.19-37

[38] P.A. Dabholkar, C.S. David, I.T. Dayle, A Comprehensive Framework for Service Quality: An Investigation of Critical Conceptual and Measurement Issues through a Longitudinal Study, Journal of Retailing 72(2), 2000, pp.139-173.

[39] C. Gronroos, A Service Quality Model and Its Marketing Implications, European Journal of Marketing 18 (4), 1984, pp. 36-44.

[40] A. Donabedian, Quality Confidence in Health Care: Consumers' Role, Quality in Health Care, 1, 1992, pp. 247-251.

[41] A. Donabedian, The Definitions of Quality and Approaches to Its Assessment: Volume I. Chicago: Health Administration Press, 1980.

[42] A. Donabedian, Evaluating the Quality of Medical Care, Milbank Memorial Fund Quarterly 44, 1966, pp.166206.

[43] R. Brook, N.W. Kathleen, Quality of Health Care for the Disadvantaged, Journal of Community Health 1 (2), 1975, pp. 132-156.

[44] Ware, John E., Mary K. Snyder,W. Russell Wright, and Allyson R. Davies, Defining and Measuring Patient Satisfaction with Medical Care, Evaluation and Program Planning 6, 1983, pp.247-263.

[45] J.E. Ware, A. Davies-Avery, and A.L. Stewart, The Measurement and Meaning of Patient Satisfaction, Health \& Medical Care Services Review 1 (1), 1978, pp. 2-15.

[46] J.H. Wiggers, K.O. Donovan, S. Redman, and R.W. Sanson-Fisher, Cancer Patient Satisfaction with Care, Cancer 66 (August), 1990, pp. 610-616.

[47] Zineldin, M., The Quality of Health Care and Patient Satisfaction: An Exploratory Investigation of the 5Qs Model at Some Egyptian and Jordanian Medical Clinics, International Journal of Health Care Quality Confidence 19 (1), 2006, pp. 60-93.

[48] Mahmood, M. A. Variables affecting Information Technology End User Satisfaction: A Meta Analysis of the Empirical Literature, International Journal of Human Computer Studies 52 (5), 2000, pp. 751-771

[49] M. Zviran, Z. Erlich, Measuring IS user satisfaction: Review \& Implications, Communications of the AIS 12, 2003, pp. 81-103.

[50] J.B. Gotlieb, G. Dhruv, W.B. Stephen, Consumer satisfaction and perceived quality: complementary or divergent constructs, Journal of applied psychology 79 (6), 1994, pp. 875-85.

[51] W.H. DeLone, E.R. McLean, Information Systems Success: The Quest for the Dependent Variable, Information Systems Research 3(1), 1992, pp. 60-95.

[52] A. Rai , S.S. Lang, R.B. Welker, Assessing the validity of IS success models: an empirical test and theoretical analysis. Information Systems Research 13(1), 2002, pp. 5-69.

[53] P.B. Seddon, A respecification and extension of the DeLone and McLean model of IS success. Information Systems Research, 1997, pp. 240-253. 
[54] V.L. Saga, R.W. Zmud, The Nature and Determinants of IT Acceptance, Routinization, and Infusion, Diffusion, Transferand Implementation of Information Technology, L. Levine (ed.), Elsevier Science, Amsterdam, 67-86, 1994.

[55] J. Jasperson, P.E. Carter, R.W. Zmud, A Comprehensive Conceptualization of Post-Adoptive Behaviors Associated with Information Technology Enabled Work Systems, MIS Quarterly 29(3), 2005, pp.525-557.

[56] M. Limayem, S.G. Hirt, C.M.K. Cheung, How habit limits the predictive power of intention: The case of information systems continuance. MIS Quarterly 31(4), 2007, pp. 705-737.

[57] A. Bhattacherjee, An Empirical Analysis of the Antecedents of Electronic Commerce Service Continuance, Decision Support Systems 32 (2), 2001a, pp. 201-214.

[58] A. Bhattacherjee, Understanding information systems continuance. An expectation-confirmation model. MIS Quarterly 25(3), 2001, pp.351-370.

[59] W.H. DeLone, E.R. McLean, The DeLone and McLean model of information systemssuccess: A ten-year update. Journal of Management Information Systems 19 (4), (Spring 2003), pp. 9-30.

[60] S. Petter, R.E. McLean, A meta analytic assessment of the DeLone and McLean IS success model: An examination of IS success at the individual level, Information \& Management 46, 2009, pp.159-166

[61] A. Parasuraman, V.A. Zeithaml, A. Malhotra, E-S-QUAL: A Multiple-Item Scale for Assessing Electronic Service Quality. Journal of Service Research 7(3), 2005, pp. 213-233.

[62] M. Chae, J. Kim, H. Kim, H. Ryu, Information quality for mobile internet services: a theoretical model with empirical validation. Electronic Markets 12, 2002, pp.38-46.

[63] R. Sousa, C. Voss, Service quality in multichannel services employing virtual channels, Journal of Service Research 8(4), 2006, pp. 356-371.

[64] B. Bitner, H. Booms, M.S. Tetreault, The Service Encounter: Diagnosing Favorable and Unfavorable Incidents, Journal of Marketing 54 (January), 1990, pp.71-84.

[65] L. Aharony, S. Strasser, Patient Satisfaction: What We Know About and What We Still Need to Explore, Medical Care Review 50 (1), 1993, pp.49-79.

[66] J.N. Sheth, I.N. Bruce, L.G. Barbara, Consumption Values and Market Choices: Theory and Applications. Cincinnati, OH: South-Western, 1991.

[67] F.D. Davis, Perceived usefulness, perceived ease of use, and user acceptance of information technology. MIS Quarterly 13(3), 1989, pp.318-346.

[68] J.C. Sweeney, G.N. Soutar, Consumer perceived value: The development of a multiple item scale, Journal of Retailing 77 (2), 2001, pp.203-220.

[69] D. Straub, M.C. Boudreau, D. Gefen, Validation Guidelines for IS Positivist Research, Communications of AIS 13 (24), 2004, pp.380-427.

[70] C.G. Moore, I. Benbasat, Development of an instrument to measure the perceptions of adopting an information technology innovation, Information Systems Research 2(3), 1991, pp.192-222.

[71] S. Petter, D. Straub, A. Rai, Specifying FormativeConstructs in Information Systems Research, MIS Quarterly 31(1), 2007, pp.623-656.

[72] K.A. Bollen, R. Lennox. Conventional Wisdom on Measurement: A Structural Equation Perspective. Psychological Bulletin110(2), 1991, pp.305-314

[73] W.W. Chin, How to write up and report PLS analyses, in Handbook of Partial Least Squares: Concepts, Methods and Application. Esposito Vinzi, V.; Chin, W.W.; Henseler, J.; Wang, H. (Eds.), Springer, Germany, pp. 645-689, (2010).

[74] J.R. Edwards, R.P. Bagozzi, On the Nature and Direction of Relationships between Constructs, Psychological Methods 5(2), 2000, pp. 155-174.

[75] C.B. Jarvis, S.B. MacKenzie, P.M. Podsakoff, A Critical Review of Construct Indicators and Measurement Model Misspecification in Marketing and Consumer Research, Journal of Consumer Research 30, 2003, pp. 199-218.

[76] M. Wetzels, G.O. Schroder, V.C. Oppen, Using PLS path modeling for assessing hierarchical construct models: Guidelines and empirical illustration, MIS Quarterly 33 (1), 2009, pp. 177-195.

[77] J.R. Edwards, Multidimensional Constructs in Organizational Behavior Research: An Integrative Analytical Framework, Organizational Research Methods 4 (2), 2001, pp.144-192.

[78] S.B. MacKenzie, P.M. Podsakoff, C.B. Jarvis, The Problem of Measurement Model Misspecification in Behavioral and Organizational Research and Some Recommended Solutions, Journal of Applied Psychology 90 (4), 2005, pp. 710-730. 
[79] R.G. Netemeyer, W.O. Bearden, S. Sharma, Scaling Procedures: Issues and Applications, Thousand Oaks, CA: Sage Publications, 2003.

[80] W.W. Chin, Issues and Opinion on Structural Equation Modeling, MIS Quarterly 22 (1), 1998a. Pp. vii-xvi.

[81] C. Fornell, F.L. Bookstein, Two Structural Equation Models: LISREL and PLS Applied to Consumer ExitVoice Theory, Journal of Marketing Research 19, 1982, pp.440-452.

[82] C. Guinot, J. Latreille, M. Tenenhaus, PLS Path Modeling and Multiple Table Analysis: Application to the Cosmetic Habits of Women in Ile-de-France, Chemometrics and Intelligent Laboratory Systems 58 (2), 2001, pp.247-259.

[83] J. B. Lohmöller, Latent Variable Path Modeling with Partial Least Squares, Heidelberg: Physica-Verlag, 1989.

[84] M. Tenenhaus, V.E. Vinzi, Y.M. Chatelin, C. Lauro, PLS Path Modeling, Computational Statistics and Data Analysis 48 (1), 2005, pp. 159-205.

[85] Wold, H. Partial Least Squares, in Encyclopedia of Statistical Sciences, S. Kotz and N. L. Johnson (eds.), Wiley, New York, 1985

[86] W.W. Chin, The Partial Least Squares Approach to Structural Equation Modeling, in Modern Business Research Methods, G. A. Marcoulides (ed.), Lawrence Erlbaum Associates, Mahwah, NJ, 1998b.

[87] B. Efron, R.J. Tibshirani, An Introduction to the Bootstrap, New York: Chapman and Hall, 1993.

[88] C. Fornell, D. F. Larcker, Evaluating Structural Equation Models with Unobservable Variables and Measurement Error, Journal of Marketing Research 18 (1), 1981, pp. 39-50.

[89] R.A. Spreng, S.B. MacKenzie, R.W. Olshavsky, A reexamination of the determinants of customer satisfaction. Journal of Marketing 60(3), 1996, 15-32.

[90] D. Iacobucci, A. Duhachek, Mediation analysis-round table acr, presentation at the round table of the ACR conference, Toronto, 2003.

[91] S. Helm, A. Eggert, I. Garnefeld, Modeling the impact of corporate reputation on customer satisfaction and loyalty using partial least squares, In V. Esposito Vinzi, W.W. Chin,J. Henseler \& H. Wang (Eds.) Handbook of partial least squares, Heidelberg: Springer, 2010.

[92] M. Sobel, Asymptotic confidence intervals for indirect effects on structural equation models. In S. Leinhardt (Ed.), Sociological Methodology Jossy-Bass, 1982, 290-312

[93] A.G. Churchill A paradigm for developing better measures of marketing constructs, Journal of Marketing Research, XVI (1979), 64-73

[94] J. Cohen, Statistical Power Analysis for the Behavioral Sciences, Hillside, NJ: Lawrence Erlbaum, 1988.

[95] H.H. Bauer, S. Barnes, S. T. Reichardt, M.M. Neumann, Driving consumer acceptance of mobile marketing: A theoretical framework and empirical study. Journal of Electronic Commerce Research, 6(3), 2005, 181-192.

[96] S.J. Barnes, Location-Based Services: The State-of-the-Art, e-Service Journal, 2(3), 2003, 59-70.

[97] S.J. Barnes, E. Scornavacca, Mobile Marketing: The Role of Permission and Acceptance, International Journal of Mobile Communications, 2(2), 2004, 128-139.

[98] P. Barwise, C. Strong, Permission-based Mobile Advertising. Journal of Interactive Marketing, 16 (1), 14-24.

[99] K. Pousttchi, D.G. Wiedemann. Mobile marketing management: marketing objectives, types and implementation techniques, Handbook of Research on Mobile Marketing Management, (Eds.) Key Poustchhi \& Dietmer G. Widemann, IGI publishing, Cambridge, USA 2009, 1-09.

[100] M. Kakihara, C. Sorensen, Expanding the 'mobility' concept, ACM SIGGROUP Bulletin, 22 (3), 2001.

[101] J.G. Kahn, J. Yang, J.S. Kahn .The potential roles of mHealth in developing economies: can they be realized? Health Affairs, 2, 2010, 254-61.

[102] D.A. Whetten, (1989). What constitutes theoretical contributions. Academy of Management Review, 14(4), 490-495.

[103] J. Teboul, Service is front stage: positioning services for value advantage. INSEAD Business Press, Palgrave MacMillan, 2006.

[104] G.L. Polites, N. Roberts, J. Thatcher, Conceptualizing models using multidimensional constructs: a review and guidelines for their use, 21, 2012, 22-48.

[105] R.P. Bagozzi, Measurement and meaning in information systems and organizational research: methodological and philosophical foundations. MIS Quarterly, 35 (2), 2011, 261-292.

[106] S.B. MacKenzie, P.M. Podsakoff, N.P. Podsakoff, Construct measurement and validation procedures in MIS and behavioral research: integrating new and existing techniques. MIS Quarterly, 35 (2), 2011, 293-334.

[107] W.W. Chin, P.R. Newsted, Structural equation modeling analysis with small samples using partial least squares. In R. Hoyle (Ed.), Statistical Strategies for Small Sample Research, Thousand Oaks, Sage Publications, CA, 307-341, 1999. 
[108] J. Hair, C.M. Ringle, M. Sarstedt, PLS-SEM: indeed a silver bullet. Journal of Marketing Theory and Practice, 19 (2), 2011, 139-151.

[109] Hulland, J., Ryan, M.J., \& Rayner, R.K. Modeling customer satisfaction: a comparative performance evaluation of covariance structure analysis versus partial least squares, in Handbook of Partial Least Squares: Concepts, Methods and Application. Esposito Vinzi, V., Chin, W.W.; Henseler, J., Wang, H. (Eds.), Springer, Germany, 307-325, 2010.

[110] S.A. Mulaik, L.R. James, J. Van Alstine, N. Bennett, S. Lind, C.D., Stilwell. Evaluation of goodness-of-fit indices for structural equation models. Psychological Bulletin. 105(3). 1989, 430-445.

[111] Ivatury, G., Moore, J., \& Bloch, A.A doctor in your pocket: health hotlines in developing countries. Innovations: Technology, Governance \& Globalization, 4(1), 2009, 119-153.

[112] W.H. Curioso, P.N. Mechael, Enhancing 'M-Health' with south-to-south collaborations. Health Affairs, 29 (2), 2010, 264-267.

[113] J.L., Feder, Cell-phone medicine brings care to patients in developing countries, 29 (2), 2010, 259-263.

[114] World Health Organization. mHealth: New horizons for health through mobile technologies: second global survey on eHealth, Geneva, 2011.

\section{Appendix 1: Demographic profile of respondents}




\begin{tabular}{|c|c|c|}
\hline Items & Categories & Statistic (\%) \\
\hline Gender & $\begin{array}{l}\text { Male } \\
\text { Female }\end{array}$ & $\begin{array}{l}60 \\
40\end{array}$ \\
\hline Age & 18-62 (direct entry) & 33 yrs (avg.) \\
\hline $\begin{array}{l}\text { Income } \\
\text { (per month in US\$) }\end{array}$ & $\begin{array}{l}<\$ 75 \\
\$ 76-\$ 150 \\
\$ 151-\$ 224 \\
\$ 225+\end{array}$ & $\begin{array}{l}47 \\
20 \\
15 \\
18\end{array}$ \\
\hline Location & $\begin{array}{l}\text { Urban } \\
\text { Rural }\end{array}$ & $\begin{array}{l}51 \\
49\end{array}$ \\
\hline Occupation & $\begin{array}{l}\text { Education, teaching \& research } \\
\text { Domestic worker/housewife } \\
\text { Personal business } \\
\text { Public organization } \\
\text { Private organization } \\
\text { Others }\end{array}$ & $\begin{array}{l}32 \\
23 \\
13 \\
7 \\
21 \\
4\end{array}$ \\
\hline
\end{tabular}

Appendix 2: Inter-rater reliability 


\begin{tabular}{|c|c|c|c|}
\hline Placement Ratios & Round 1 & Round 2 & Avg. (2 Rounds) \\
\hline System reliability & 0.82 & 0.84 & 0.83 \\
\hline System efficiency & 0.74 & 0.78 & 0.76 \\
\hline System privacy & 0.86 & 0.92 & 0.89 \\
\hline Cooperation & 0.82 & 0.76 & 0.79 \\
\hline Confidence & 0.84 & 0.88 & 0.86 \\
\hline Care & 0.72 & 0.84 & 0.78 \\
\hline Utilitarian benefits & 0.82 & 0.88 & 0.85 \\
\hline Hedonic benefits & 0.75 & 0.81 & 0.78 \\
\hline Average & 0.80 & 0.84 & 0.82 \\
\hline \multirow{8}{*}{ Raw Agreement } & 0.86 & 0.82 & 0.84 \\
\hline & 0.84 & 0.86 & 0.85 \\
\hline & 0.88 & 0.94 & 0.91 \\
\hline & 0.84 & 0.92 & 0.88 \\
\hline & 0.86 & 0.86 & 0.86 \\
\hline & 0.78 & 0.92 & 0.85 \\
\hline & 0.85 & 0.88 & 0.87 \\
\hline & 0.82 & 0.86 & 0.84 \\
\hline Average & 0.84 & 0.88 & 0.86 \\
\hline \multirow[t]{2}{*}{ Cohen's Kappa } & 0.83 & 0.79 & 0.81 \\
\hline & 0.81 & 0.82 & 0.82 \\
\hline \multirow{3}{*}{$K=\frac{p r(a)-p r(e)}{1-p r(e)}$} & 0.84 & 0.91 & 0.88 \\
\hline & 0.8 & 0.89 & 0.84 \\
\hline & 0.82 & 0.82 & 0.82 \\
\hline \multirow{4}{*}{$\begin{array}{l}* \operatorname{Pr}(a)=\text { the observed } \\
\text { percentage agreement, } \operatorname{Pr}(e)= \\
\text { the probability of random } \\
\text { agreement }\end{array}$} & 0.75 & 0.82 & 0.79 \\
\hline & 0.83 & 0.86 & 0.84 \\
\hline & 0.79 & 0.82 & \\
\hline & & & 0.81 \\
\hline Average & 0.81 & 0.84 & $\mathbf{0 . 8 3}$ \\
\hline
\end{tabular}

Appendix 3: Equations for hierarchical modeling using PLS [73, 76, 85] 


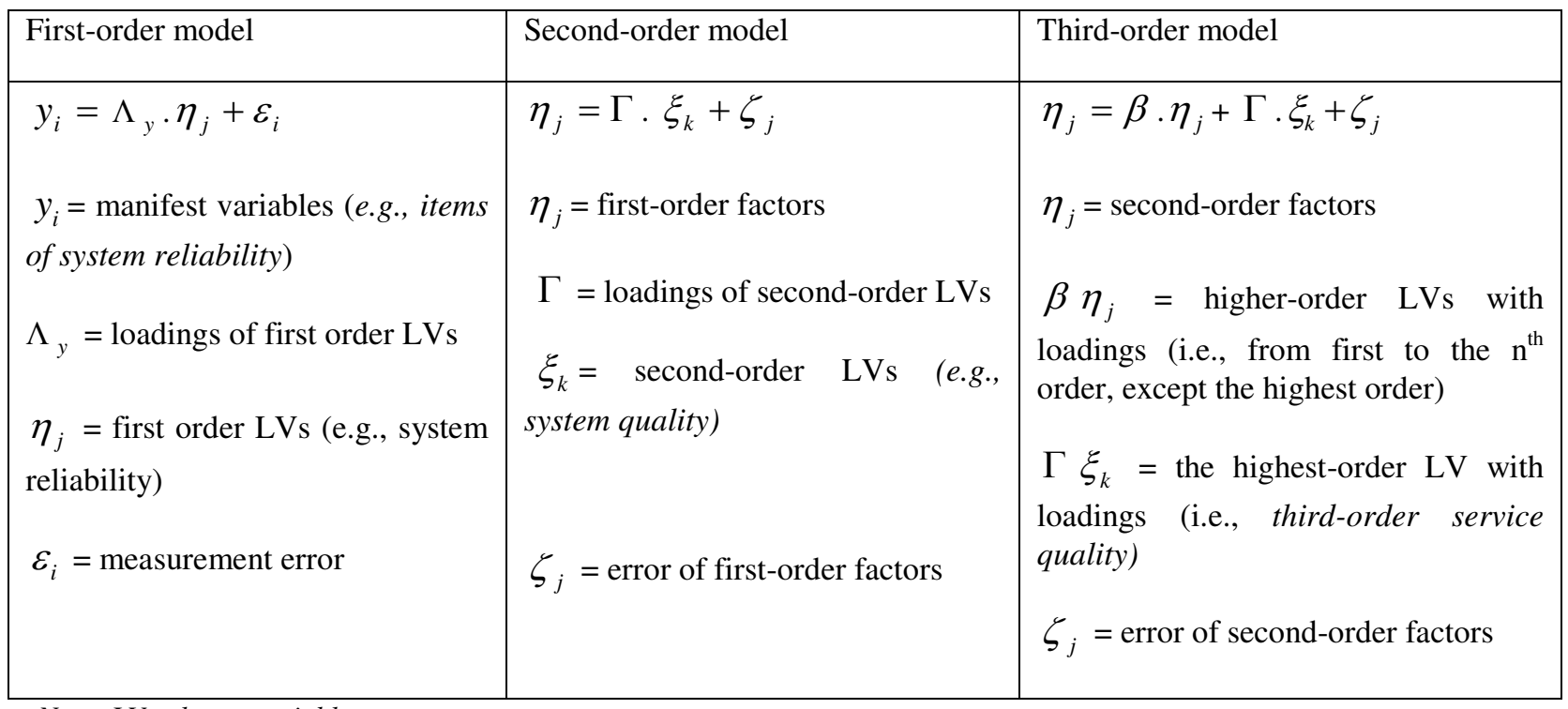

Note: $L V=$ latent variables

\section{Appendix 4: mHealth Service Quality Model}

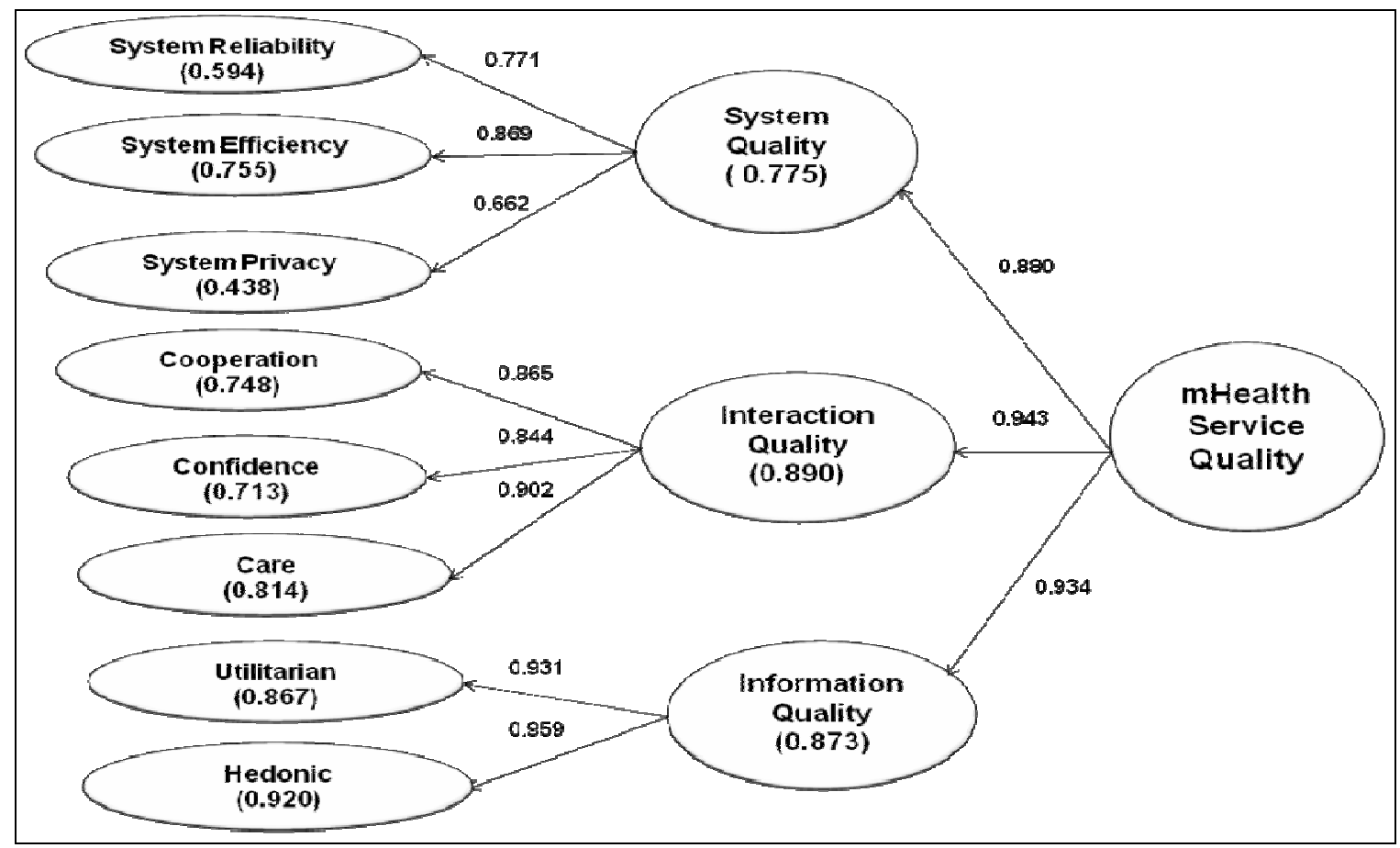

\section{Appendix 5: Path coefficients and $t$-statistics}




\begin{tabular}{|l|c|c|c|}
\hline Paths in the Research Model & Path coefficients & Standard Error & T-Statistics \\
\hline System Quality -> System Efficiency & 0.869 & 0.014529 & 59.782 \\
\hline System Quality -> System Privacy & 0.662 & 0.055169 & 12.000 \\
\hline System Quality -> System Reliability & 0.771 & 0.039473 & 19.532 \\
\hline Interaction Quality -> Confidence & 0.844 & 0.022992 & 36.732 \\
\hline Interaction Quality -> Care & 0.902 & 0.015749 & 57.288 \\
\hline Interaction Quality -> Cooperation & 0.865 & 0.026224 & 32.982 \\
\hline Information Quality -> Hedonic Benefits & 0.959 & 0.005846 & 164.044 \\
\hline Information Quality -> Utilitarian Benefits & 0.931 & 0.011298 & 82.395 \\
\hline Service Quality -> System Quality & 0.880 & 0.019567 & 44.863 \\
\hline Service Quality -> Interaction Quality & 0.943 & 0.009257 & 101.957 \\
\hline Service Quality -> Information Quality & 0.934 & 0.008979 & 104.231 \\
\hline Service Quality -> Satisfaction & 0.779 & 0.034368 & 22.680 \\
\hline Service Quality -> Continuance & 0.358 & 0.063581 & 5.636 \\
\hline Satisfaction -> Continuance & 0.449 & 0.063629 & 7.053 \\
\hline
\end{tabular}

\section{Appendix 6: Scale development process}




\begin{tabular}{|c|c|}
\hline Steps & Process \\
\hline $\begin{array}{l}\text { Step 1: Conceptualization } \\
\text { of constructs }\end{array}$ & $\begin{array}{l}\text { Developed the conceptual definition of the constructs using the } \\
\text { theoretical background. }\end{array}$ \\
\hline $\begin{array}{l}\text { Step 2: Development of } \\
\text { measures }\end{array}$ & $\begin{array}{l}\text { 2.1 Generated items for constructs using qualitative study (i.e., focus } \\
\text { group discussions and in-depth interviews). } \\
\text { 2.2 Confirmed content validity of items using Q-sort procedures. }\end{array}$ \\
\hline $\begin{array}{l}\text { Step 3: Model } \\
\text { specification }\end{array}$ & $\begin{array}{l}\text { Specified the measurement model as a third-order, reflective, } \\
\text { multidimensional model. }\end{array}$ \\
\hline $\begin{array}{l}\text { Step 4: Scale evaluation } \\
\text { and refinement }\end{array}$ & $\begin{array}{l}\text { 4.1 Collected data to conduct pretest }(\mathrm{n}=15) \text { and pilot study }(\mathrm{n}=110) \text {. } \\
\text { 4.2 Purified and refined scale using EFA by dropping seven items (i.e., } \\
\text { SQ4, SQ8, SQ11, SQ15, SQ18, SQ19 and SQ26). }\end{array}$ \\
\hline Step 5: Scale validation & $\begin{array}{l}\text { 5.1 Gathered data from new sample }(305) \text { and applied CFA (i.e., } \\
\text { component-based SEM) to re-examine scale properties of the hierarchical } \\
\text { model. } \\
5.2 \text { Confirmed scale reliability (i.e., AVE }>0.50 \text {, CR }>0.80 \text { ), convergent } \\
\text { validity (i.e., loadings }>0.70 \text { ), discriminant validity (i.e., cross loadings, } \\
\left.\sqrt{A V E}>\text { correlations), nomological validity (i.e., } R^{2}>0.30\right) \text { and } \\
\left.\text { predictive validity (i.e., } Q^{2}>0\right) \text {. } \\
5.3 \text { Confirmed overall parameters using power analysis }(>0.80) \text { and } \\
\text { global fit index }(>0.36) \text {. }\end{array}$ \\
\hline $\begin{array}{l}\text { Step 6: Linking the new } \\
\text { scale with theory, method } \\
\text { and practice. }\end{array}$ & $\begin{array}{l}\text { 6.1 Theory: Extended service quality theory in mHealth by developing } \\
\text { the third-order, hierarchical, multidimensional model. } \\
\text { 6.2 Method: Confirmed the measures and structural associations of the } \\
\text { hierarchical model using component-based SEM or PLS path modeling. } \\
\text { 6.3 Practice: Developed a tool for conducting an integrated analysis and } \\
\text { design of mHealth service systems at dimensional, subdimensional and } \\
\text { overall levels. }\end{array}$ \\
\hline
\end{tabular}

